\title{
Euro y políticas públicas: algunas reflexiones a propósito de la moneda única europea
}

\section{M. ${ }^{a}$ Dolores de la Puente-Campano Fernández *}

En enero de 2002 el euro será moneda de uso efectivo. Pero si hubiera que singularizar un «año del euro», sería 1998, cuando se decidió en qué consistía y hacia dónde caminaría la Unión Económica y Monetaria (UEM). Una unión que se ha calificado de «novedosa» (con permiso de los lingüistas contrarios al término), pero que a decir verdad ya estaba presente en quienes lideraron aquellos primigenios movimientos de unidad europea que encontraron su primera regulación expresa en el Tratado de Roma (1957) y, tras sucesivos avatares, condujeron hasta el Acta Única (1986), Maastricht (TUE 1992), Amsterdam (1997) y Niza (diciembre 2000), sin menoscabo de otros relevantes hitos en el tantas veces tortuoso camino de una unificación no exenta de polémica e interrogantes. El euro es ya la moneda única europea y con ella los Quince, aunque por distintas causas se hayan incorporado a la misma Doce, pretendieron simultanear la creación de empleo y la mejora de la competitividad frente al exterior, sin dejar de salvaguardar el tan caro (querido y costoso) Estado del Bienestar. De este modo, empleo, competitividad y bienestar se erigieron en objetivos prioritarios, para cuya consecución y mantenimiento se tuvieron que acordar, con la finalidad de un cumplimiento permanente, tres criterios de convergencia de carácter ineludible para quienes pretendieran participar en la unificación monetaria, en definitiva, en el euro, desde enero de 1999.

A fin de seguir el discurso de las reflexiones que, a propósito del euro más que sobre él, aquí serán abordadas, resultará de utilidad recordar los tan reiterados criterios de compromiso para aspirantes y socios: un déficit público inferior al 3 por 100 del
PIB, una inflación que no supere el 3 por 100 y una deuda pública por debajo del 60 por 100 del Producto Interior Bruto (PIB). También se estableció el compromiso de mantener estables el precio del dinero y el tipo de cambio. Ambicioso proyecto que ha devenido una realidad harto delicada y que viene acompañado desde su origen por una fundamentada polémica que se sustenta en ciertos interrogantes suscitados en cuanto se efectúan algunas reflexiones. Para discurrir sobre dichos interrogantes y abrir sus posibles respuestas se hace necesario volver la vista hacia acontecimientos que resultaron determinantes en el reciente pasado, así como hacia fenómenos que han definido y están definiendo su escenario actual.

\section{A propósito de la unificación monetaria}

Cuando finalizó la Ronda Uruguay del Acuerdo General sobre Aranceles de Aduanas y Comercio (GATT 1996) quedó establecida una liberalización del comercio impensable hasta ese momento y además se acordó propiciar su extensión a escala mundial. Los hasta entonces superprotegidos espacios comerciales (estatales o supranacionales) se autoimpusieron levantar las barreras fronterizas a la importación de una considerable cantidad de productos, con lo que se estaba reconociendo de facto el fenómeno que ha dado en denominarse globalización 
de la economía, hoy tan contestada por ciertos sectores, asumiéndose las consecuencias de lo que habría de implicar tal decisión. Decisión reiterada de forma explícita tras la reunión del G-8 (inclusión de Rusia) en Okinawa (julio 2000), cuyo documento final incluyó el objetivo de redoblar esfuerzos para celebrar una nueva ronda a fin de liberalizar el comercio. Una renovada apuesta por la globalización (reuniones en Seattle de la OMC y en Praga del FMI y BM en el otoño del 2000 a las que se vinieron a añadir otras) que tanta protesta ha suscitado en la calle, las ONG, foros especializados e instituciones diversas. Fenómeno que se habrá de describir más adelante, puesto que reflexionar a propósito del euro conduce a analizar distintas cuestiones más allá de la estricta implantación de una moneda común a una serie de países en exclusivos términos monetarios, de mercados financieros, o en cuanto a las implicaciones de su implantación en determinados sectores económicos. Éste no es el objeto directo de las presentes reflexiones.

Antes de 1996 (octava conferencia del GATT) las defensas arancelarias de la Unión Europea se contaban entre las más elevadas y «fortificadas» del mundo, por lo que la Ronda Uruguay presentó para la Europa común una decidida apuesta por la inmersión en el nuevo escenario de la competitividad librecambista mundial. Pero si la Europa comunitaria se había instalado hasta entonces en un mecanismo de elevada y férrea protección arancelaria y en unos también elevadísimos precios de mercado, ello obedecía con carácter prácticamente obligado, sobre otras razones de indudable peso, al complejo sistema público de amparo social que constituía y constituye la base de su denominado Estado del Bienestar. Ese bienestar europeo conforma un ciclo en el cual resulta obligado para el productor repercutir en los precios de venta al por mayor el coste social de sus trabajadores (pensiones, sanidad, desempleo) y además tiene que ingresar el valor de esas prestaciones en las arcas del Estado para que éste a su vez pueda prestar a los ciudadanos la protección a la que está comprometido, en la mayoría de los casos constitucionalmente. Dicha compleja red de beneficios depara a la postre unos elevados déficits públicos, pues tiende a incrementarse la distancia entre lo que el Estado ingresa y lo que gasta en sostener unas conquistas sociales irrenunciables. Así, cuando el empresario europeo reflejaba dichas cargas en sus precios finales, en definitiva estaba perdiendo competitividad frente a otros productos iguales que se elaboraban en países menos protegidos socialmente, como eran, en un ejemplo ya tópico, las economías entonces emergentes del Extremo Oriente o Sureste Asiático; «milagro asiático», por-otra parte, hoy sensiblemente modificado y caído en desuso. Consecuentemente, en un escenario de liberalización del comercio internacional cada vez más intensamente propiciado, los países de dichas áreas se situaban de partida en una evidente posición de ventaja, ya que entre otras razones contaban (y cuentan) con una masa de trabajadores destajistas y desprotegidos socialmente, lo que repercutía de inmediato en unos precios más competitivos para sus productos. También Estados Unidos competía en ese sentido con ventaja, admitidas todas las salvedades oportunas a la comparación, pues la protección social en dicho pais tiene otra entidad y dibuja otros rasgos muy específicos, pero en todo caso se decanta globalmente inferior a la de la Europa comunitaria, probablemente con la única excepción de las pensiones de jubilación (Social Security). Y ningún gobierno ni partido político de Europa occidental, bien esté en el poder o en la oposición, se plantearía proponer un recorte drástico en el Estado de Bienestar con el fin de ganar competitividad frente al exterior, reduciendo por ese camino el déficit público. De ahí que la forma más coherente y operativa de adaptarse a la nueva situación liberalizadora sin tomar medidas impopulares, con el consiguiente coste de votos, se planteó a través de la unificación monetaria de los Quince que brindaba una posibilidad de «blindaje» para resistir y afrontar sin excesivos traumas la nueva e inexorable etapa liberalizadora de globalización de la economía, manteniendo simultáneamente sus modelos institucionalizados de cobertura social. Esta explicación sumamente sintética constituye sólo una descripción generalista que no por ello excluye la consideración de otras razones causales con indudable influencia y de índole no sólo económico-social.

La unificación monetaria planteaba, pues, entonces serios interrogantes, no pocos de los cuales perviven hoy, habiéndose añadido otros con un euro que continúa debatiéndose por estabilizarse tras serios varapalos pero que todavía adolece de una severa volatilidad, aunque la desaceleración (no parece todavía recesión) americana - a decir de alguna corriente de opiniónpudiera significar su despegue a partir del año 2001. Sin embargo, dicha Unión también cuenta intrínsecamente con evidentes ventajas que quizás precisamente en estos tiempos de cierto «euroescepticismo» se haga más oportuno poner de manifiesto. $\mathrm{Al}$ menos tiene tres. Una de ellas estriba en que exige a los Estados socios la reducción y control posterior de una serie de magnitudes básicas para su salud financiera, tales como el déficit, la inflación y la deuda pública. Otra es que con la unificación se continuará salvaguardando la cobertura social de protección. Pero la más significativa ventaja consiste en que se disenó la Unión Monetaria de manera que dotara a la Comunidad Europea de una considerable potencia financiera, pudiendo competir el euro como moneda de transacción mundial junto con el dólar (no necesariamente contra él). Difícil competencia por otra parte, tal y como se ha evidenciado especialmente en el segundo semestre del año 2000 que se prolonga en el 2001. No obstante; así estaba concebido y de este modo se pretende llegue a operar mediante la aplicación de las oportunas medidas, seguramente tanto a uno como al otro lado de la zona euro, que reconduzcan las aparentemente inmanejables e indudablemente vertiginosas fluctuaciones de los globalizados mercados.

Constatadas las ventajas básicas de partida, inmediatamente afloraron los interrogantes en cuanto se procedía a reflexionar 
sobre ciertas cuestiones, que se están evidenciando más si cabe en el complicado, súbitamente cambiante y difícilmente analizable ciclo actual.

\section{A propósito de las políticas comunitarias}

Se puede comenzar reflexionando sobre las políticas presupuestarias y fiscales de los Estados miembros. La unificación basa su sistema en una autoridad monetaria central (BCE de Frankfurt) con autonomía decisoria sobre la política monetaria de la Unión, pero al tiempo cada gobierno diseña autonómicamente sus propias políticas fiscales y presupuestarias. Políticas que hoy son doce en la zona euro y quince en la UE, pero que en un horizonte próximo serán dieciocho y no tan lejano veintisiete e incluso hasta treinta. De este modo se complicaría casi permanentemente la estabilidad cambiaria del euro, pues no resulta disparatado discurrir que, cuando la nueva moneda esté circulando, se produzcan razones internas en cada socio, sobre todo con un trasfondo político y electoral, que induzcan a políticas fiscales y presupuestarias, si no opuestas, al menos sí divergentes con los criterios monetarios del Banco Central Europeo. De hecho, ya se han reclamado expresamente por algunos Estados miembros las aplicaciones específicas de unas políticas presupuestaria y fiscal comunitarias comunes, a las que ha venido a sumarse la inmigratoria. No únicas, sino comunes. Algo se ha movido, no obstante, en este sentido tras el acuerdo de armonización fiscal del ahorro gravando los rendimientos del capital que fue alcanzado por el Ecofin en el mes de noviembre de 2000, aunque la aplicación real de la directiva se haya de enfrentar a considerables obstáculos y sombras. Efectivamente, el Ecofin dio mandato al grupo de sabios independientes para que presentaran ante el Consejo Europeo de Estocolmo (primavera del 2001) las propuestas oportunas para crear un mercado financiero integrado y de un único regulador. La conversión en realidad de este acuerdo armonizador tiene por delante nueve años y dos etapas: conversaciones con países terceros antes de diciembre de 2002 (Estados Unidos, Suiza, Liechtenstein, Andorra, Mónaco, San Marino e Islas del Canal de la Mancha) para que se asocien a las reglas de los Quince y acepten informar a las haciendas europeas, y aplicación de una fase transitoria (1 de enero de los años 2003, 2006 y 2010). También se ha elaborado una lista de sesenta y seis regímenes fiscales considerados potencialmente perniciosos para el mercado interior que tendrán que estar desmantelados en enero del 2003 o, en casos especiales, en el año 2005 a más tardar. Se ha afirmado que con esta medida «se creaba un poco más de Europa», y a pesar de las carencias, de su complejidad y de su largo término, la afirmación no parece exagerada aun asumiendo todas las reservas que puedan plantearse en cuanto a que resulte más un gesto o una necesidad que una realidad operativa. Y algo también se ha movido cuando la Comisión Europea censuró por primera vez el presupuesto de un país miembro (Irlanda) en enero del 2001 recomendando que se modifique y acomode a los objetivos globales de la Unión. Asimismo, aunque de manera menos «contundente», la Comisión advirtió a Francia e Italia que controlaran sus déficits públicos.

Sin embargo, todo apunta a que estas actuaciones no dejan de ser poco más que gestos, habida cuenta el constatado exigüe entusiasmo que han mostrado los Estados miembros de la UE durante los últimos veinte años respecto a avanzar en la ansiada armonización fiscal. Y el problema se agudiza en la zona euro. El propio ejemplo de Irlanda pone de manifiesto la distorsión. Por ejemplo, su tipo en el Impuesto sobre Sociedades es del 20 por 100 , estando previsto que baje al 12,5 por 100 en el año 2003, lo que le aleja sustancialmente de la media europea. Tras la mencionada llamada de atención de la Comisión, Irlanda respondió reduciendo la presión fiscal por un importe de 1.920 millones de euros distribuidos entre diversos impuestos y tasas, así como con un recorte de los tipos impositivos para 1,2 millones de contribuyentes. Y es que Irlanda, el llamado «Tigre Verde», que ha estado creciendo a un ritmo medio del 8 por 100 anual, habiendo llegado al 10,7 por 100 en el año 2000, parece haber apostado por convertirse en una especie de paraíso fiscal. Póngase esto en relación con el acuerdo del Ecofin en noviembre. Además, la cumbre de Niza ha supuesto un apreciable paso atrás en la armonización fiscal, llegando a sustituir, en el caso de las empresas, dicha expresión por la de cooperación fiscal. La coordinación, la armonización, la puesta en común de las políticas fiscales en la zona euro, sobre todo en lo que se refiere a la imposición directa, constituye sin duda una «gruesa» asignatura pendiente. Queda también pendiente un acuerdo armonizador sobre el régimen definitivo del IVA, pues no hay que olvidar que se está en un sistema provisional de tributación en destino, cuando en el definitivo se establecerá la tributación en origen. Por no recordar la imposición sobre los productos energéticos, el alcohol, tabaco u otros impuestos éspeciales. A pesar del mencionado acuerdo sobre fiscalidad del ahorro, bien pudiera suceder que la armonización se acabe alcanzando más a través de la competencia fiscal de los Estados miembros por medio de las rebajas que se producen, sobre todo en vísperas electorales, que por las medidas armonizadoras de las instituciones europeas. La propuesta (Bélgica) de crear un impuesto europeo que propiciara la financiación directa de la UE volvió a mostrar profundas grietas entre los países miembros no sólo respecto a su oportunidad, sino sobre las modalidades a aplicar para tal financiación.

En este aspecto de puesta en común de políticas espe: cíficas puede caber otro argumento reflexivo en sentido con- 
trario, pues cuando en todos los órdenes y ámbitos se está caminando hacia la descentralización en la toma de decisiones como garantía de una mayor eficacia y eficiencia dentro de la globalización, y se están reforzando, como compensación a dos fuerzas aparentemente divergentes, los mecanismos de coordinación y cooperación intracomunitaria, la Comunidad Europea se ha decantado por la concentración del poder monetario en una sola institución. Resulta un tanto llamativo que el principio de subsidiariedad recogido en el TUE no salga precisamente reforzado en una estructura funcional que tiende a concentrar de este modo la política monetaria, aunque sea necesario por la propia naturaleza del proceso. Desde este exclusivo punto de vista y expresado en una pura lógica cartesiana, parecería un contrasentido seguir concentrado en instituciones únicas algunos de los distintos resortes económicos. Otra cosa es que llegue a resultar hasta imprescindible poner en común determinadas políticas concretas o algunas de sus medidas. Ciertamente cabe toda una doctrina respecto a la dimensión de la puesta en común de políticas públicas o la armonización de las mismas, sin detrimento del principio de subsidiariedad.

Por otra parte, también se produce con frecuencia la impresión de que la Unión Monetaria haya pretendido reproducir el hasta hace poco tan exitoso modelo de Reserva Federal estadounidense, al que observa de cerca y del que, debe admitirse, depende en considerable medida. Pero en Europa, al contrario que en Estados Unidos, ya se ha apuntado que difícilmente se ponen en común las políticas económicas, fiscales y presupuestarias por más que se armonicen (de nuevo la dicotomía) y todavía no existe un único mercado de trabajo europeo sin trabas administrativas efectivas que permitan la auténtica libre circulación de trabajadores. Objetivo también proclamadamente pretendido, pero que se presenta ciertamente complicado habida cuenta las diferentes cifras de desempleo entre los países de la Unión Europea e incluso entre los doce socios de la unificación monetaria; máxime si se analizan las diferentes estructuras de los mercados de trabajo y la diversidad de políticas laborales. Ello sin entrar a valorar el enorme y diferente impacto inmigratorio en los países miembros, lo que implicaría otro interrogante añadido. Baste en este último aspecto dejar constancia que el 70 por 100 del aumento en la población europea corresponde a la inmigración. La UE suma 377,6 millones de habitantes, según datos de Eurostat a 1 de enero del 2001, lo que supone un crecimiento de 1.150.000 personas que se distribuyen entre la llegada de 816.000 inmigrantes y un crecimiento vegetativo de 343.000 personas. Siempre según Eurostat, este flujo migratorio ha sido el más elevado en la historia de la UE, distribuyéndose de manera muy irregular, puesto que Alemania, Italia y Reino Unido concentran el 70 por 100 del flujo migratorio, mientras que España, Francia y Finlandia registran el menor impacto. Luxemburgo es el país con mayor tasa relativa de inmigración, pues registra 1,14 por cada 100 habitantes, mientras que en Finlandia y Francia sólo representa el 0,06 y 0,08 por cada 100 habitantes, respectivamente. Sin embargo, a pesar de los 816.000 inmigrantes recibidos, se argumenta que todavía son insuficientes para mantener el mero nivel de reposición de la población europea (según Eurostat se necesitan a tal fin 1,4 millones de inmigrantes anuales). España, a su vez, recibe 0,10 inmigrantes por cada 100 habitantes (entendiendo recibir por regularizar y asumir, no como receptor primero en su condición de puerta de entrada, sobre todo, desde África y Latinoamérica), lo que supone todavía un impacto muy inferior a la media europea. Estos apuntes someros de cifras ayudan a enmarcar una realidad que desde otras percepciones, incluida la mediática, pueden inducir a error. Sin embargo, las últimas llegadas masivas de inmigrantes «indocumentados» están modificando no sólo las estadísticas, sino los destinos prioritarios, que ahora son Francia, Italia y España, sin poderse cuantificar los datos reales de «ilegales», hasta el punto de que esta realidad ha provocado la celebración de una conferencia específica en otoño del 2001 en Laeken (Bruselas) a fin de poner en común los Quine su política inmigratoria con la colaboración de Naciones Unidad, distintas ONG y organismos internacionales. Aunque de nuevo el problema reside en las discrepancias internas respecto al «reparto de la carga», pues mientras Londres, como es usual, opta por mantener su propia politica, Alemania o Bélgica han manifestado la necesidad de buscar un más racional equilibrio de acogida.

Una nueva reflexión a propósito del euro que también pudiera tener cabida aquí, se refiere al distinto nivel real de desarrollo entre los miembros de la Unión, aun quedando claro que globalmente todos ellos se sitúan en estatus elevados tanto respecto al resto del mundo como en cuanto a sus propios vecinos continentales y que se han producido notables acercamientos. Es sabido que la política monetaria ha venido siendo un utensilio fundamental para crear desarrollo, y a pesar de que los gobiernos han perdido el protagonismo en dicha política al detentarla el Banco Central Europeo, y de que ese protagonismo está siendo asumido por la política fiscal, lo que provoca que ésta devenga continuamente cambiante, lo cierto es que se venía utilizando el tipo de cambio mediante devaluaciones o revaluaciones para favorecer los mercados. Procedimiento probablemente poco ortodoxo, pero ya se sabe que devaluar frena las importaciones y fomenta las exportaciones, el turismo $y$, a la postre, el empleo. Así que cuando ese instrumento monetario no se puede utilizar y, aun disponiendo de otros supletorios, los países con mayor tasa de desempleo podrían incrementar su distancia respecto a los más favorecidos de entre sus propios socios, máxime cuando los fondos europeos como vía de ayuda compensatoria han sido sometidos a revisión y no parecen una clara solución para quienes accedieron en la primera fase a la moneda única. Aparte de que se vislumbra (Niza, diciembre del 2000) ceder gran parte de esos fondos 
a los países próximos miembros de la Europa Oriental. Las diferencias estructurales, pues, siguen representando todavía un obstáculo de difícil superación a corto y medio plazo, que apunta a agravarse con la ampliación de la UE. Una reflexión esta última que se abordará más adelante también a propósito del euro.

En cuanto al Pacto de Estabilidad y Crecimiento resulta conveniente recordar que con la finalidad de aproximar voluntades como consecuencia de las diferentes políticas fiscales y presupuestarias y con el propósito de evitar que los países europeos más ricos «pagaran las alegrias» de los más débiles, los Quince se pusieron de acuerdo en el Consejo Europeo de Amsterdam en 1997 para suscribir el citado Pacto. Y el acuerdo incluía la aplicación de sanciones a quienes superaran el 3 por 100 del déficit, de manera que por cada décima porcentual en que se rebasara dicho objetivo se impone una sanción del 0,25 por 100 sobre la cifra total del PIB restringiendo, además, el acceso del país infractor a los fondos estructurales. Esta medida implicaba un sistema punitivo que, de aplicarse estrictamente, pudiera incidir aún más en el agravamiento del déficit, ante lo cual los países de economías más débiles no podrían incrementar el gasto público para combatir el desempleo que se generaría en dicho escenario ni tampoco disminuir la presión fiscal, pues habría que financiar la multa además del déficit. Hipótesis reflexiva que hubiera podido convertirse en realidad con ciertas coordenadas y para determinados socios de la UEM, aunque en las coordenadas actuales se ha desdibujado.

Otras reflexiones añadidas respecto al déficit apuntan a si resultaría excesivo imaginar en algún momento en algún país europeo cierta coyuntura al estilo de la japonesa de 1997 en la que el Estado se viera obligado a sacar a flote con dinero público entidades financieras privadas. $\mathrm{O}$ si es exagerada la hipótesis de una amenaza de conflicto bélico entre un país miembro frente a un tercero, lo que obligaría a incrementar su presupuesto de defensa, no pareciendo, si nos atenemos a experiencia anteriores, que el resto de los socios de la Unión estuvieran dispuestos a colaborar sufragando alguna parte del esfuerzo bélico de otro socio. Valga como botón de muestra, por más que parezca lejano, el caso de las Malvinas en 1982 cuando el Reino Unido obtuvo una contundente división de opiniones comunitaria encontrando ayuda en Estados Unidos, o valga el ejemplo de un eventual recrudecimiento en el viejo contencioso greco-turco. Ello a pesar de los concretos avances en la política de seguridad y defensa común, cuestión esta que no va a ser analizada a propósito del euro, aunque haya de reconocerse y dejar constancia aquí de que a través de dichos avances también se esté «baciendo más Europa», por adoptar una expresión bastante repetida en los últimos tiempos.

\section{A propósito de otras monedas y de la convergencia}

Sin embargo, sí parece oportuno efectuar una breve referencia al yen, moneda de indudable significación en el juego internacional, cuyo comportamiento ha mostrado lo que el propio Wim Duisenberg, presidente del BCE, calificó en su momento de «extraña fortaleza» e «incógnita». Los analistas de la más pura ortodoxia siguen manteniendo que el euro, pese a todo, debiera haber mostrado a lo largo del período 1999-2000 más fortaleza frente al dólar y al yen que cuando nació (enero de 1999), y, sin embargo, el mercado americano ha «castigado» a la moneda única mientras premiaba «al peor alumno», Japón, quien consiguió en un determinado período conjugar moneda fuerte y exportaciones. La fortaleza del yen desde 1999 al 2000 , aunque bruscamente frenada con posterioridad, ha venido a contradecir las teorías tradicionales según las cuales un país fundamentalmente exportador como Japón necesitaría una moneda débil para vender más y acelerar la actividad económica. La explicación al repunte del yen ha residido, para algunos analistas, en la repatriación de capitales que se inició con la mencionada crisis de 1997 y se aceleró al abandonar posiciones en Europa, precisamente a causa de la debilidad del euro. Habría de concluirse, entonces, que han sido las propias con. tradicciones del mercado las que hundían la divisa europea, elevaban la japonesa y consolidaban el modelo americano como hegemónico. La ortodoxia, sin embargo, recetaba (y receta) más reformas estructurales y más mercado, aunque el mercado se equivoque, $y$, a propósito de los hechos, asevera que fue el «patriotismo» el que hizo al yen regresar a Japón en tiempos de crisis y reforzaba el dólar en vísperas de elecciones en Estados Unidos e incluso durante el conflictivo y dilatado resultado de las mismas; mientras que en Europa - afirma - el mercado y la divisa no tiene una sola patria. Es ésta una interpretación de corte «patriótico» que a finales del 2000 se ha reiterado a propósito de otros acontecimientos, como el resultado del referéndum danés, y que suele formar parte argumental del discurso interpretativo de algunos analistas.

En cuanto a los criterios de convergencia establecidos en un momento determinado de cara al examen de entrada, su permanencia está afectada seriamente por aspectos coyunturales, pues cualquier cambio en cualquier macromagnitud puede dar al traste - de hecho ha dado- con algunos de ellos. La mayoría de los Quince, no sólo los entonces Once, han utilizado al máximo elementos contables para alcanzar los criterios de convergencia y cumplir el Pacto de Estabilidad y Crecimiento, y las privatizaciones de empresas públicas como posible instrumento paliativo del déficit y deuda pública se han revelado medidas estrictamente coyunturales. Además, la casi impensable 
reducción de las prestaciones que implica el bienestar, aun siendo posibles medidas estructurales, ya se ha apuntado que resultan impopulares, restando votos en unos Estados miembros que constituyen democracias representativas, por lo que cualquier partido político difícilmente adoptará este tipo de soluciones en las consolidadas democracias sociales europeas. De ahí se plantea una nueva reflexión referida al denominado «tresporcientismo». La mayoría de los expertos están de acuerdo en que la Unión Monetaria no podía ni puede salir adelante sin la participación de Francia y Alemania, países, por cierto, que para cumplir el «tres coma cero por ciento» en inflación y déficit también han sufrido un auténtico stress contable, y eso que el criterio del «tres por ciento y ni una décima más» es alemán. Pero esta doctrina alemana llevada a sus límites podría deparar dos zonas monetarias: una alrededor del euro y otra, bien voluntaria (Inglaterra, Suecia y ahora Dinamarca) o por obligación, con sus propias divisas. Y la interrelación entre ambas zonas (máxime si se consideran los países de la ampliación) presenta serias incógnitas aun en una UE reformada institucionalmente. Ello con independencia y además del difícil cumplimiento continuado del 3 por 100 , para lo que no hay más que leer las cifras europeas de inflación en el otoño del 2000 agravadas en el 2001, con o sin impacto de la crisis petrolifera que azotó las economías occidentales en dichas fechas. «Azote», por otra parte, que subyace en el horizonte como telón de fondo permanente.

Los sectores críticos al proceso de unificación monetaria, sobre todo los procedentes de la izquierda política, concluían que la causa más influyente en las preocupantes tasas de paro de buena parte de los países comunitarios provenía de las rigurosas políticas monetarias que habían venido aplicando los distintos bancos centrales nacionales, generando deflación como medio de fomentar la competitividad. Y esto no es cierto como explicación absoluta ni prioritaria porque la causa del elevado paro no ha estribado ni única ni principalmente en las políticas monetarias, sino que una gran responsabilidad corresponde precisamente a la liberalización del comercio mundial acordada en la Ronda Uruguay del GATT y la consiguiente inmersión en la globalización económica. De tal manera que el panorama actual se fotografía en que, por un lado, se continúa en la recta final e inicial de un euro con base monetarista liberal (en su concepto y las condiciones del entorno), y, por otro, que en los Estados miembros perviven criterios keynesianos en lo que se refiere a la protección social, manteniendo todavía una elevada imposición sobre el trabajo y los beneficios empresariales, y regulando excesivamente el mercado laboral con la pervivencia de unos convenios colectivos que todavía dificultan a las empresas para ajustarse a las nuevas tendencias ultraliberales del mercado, aun contando con las sucesivas reformas laborales que vienen siendo implantadas.

Un breve repaso a la situación reciente (año 2000) presidida por un euro tambaleante revela un plano sobre el que se impri- men, de una parte, las dificultades del «tresporcientismo» y, de otra, la evidente distancia entre las economías europea y norteamericana, aunque la crisis les haya aproximado. La sombra de la inflación planea sobre Europa y el propio BCE admitió no sólo que los precios constituyen «la gran mancha» de las economías europeas, sino que además propenderían a incrementarse al menos a corto plazo, lo que, de producirse en elevados porcentajes, forzaría a modificar sistemáticamente los tipos de interés en la zona euro. La foto fija de la reciente situación ha mostrado la evidencia de unos datos españoles de inflación preocupantes, pero Alemania, la «inventora del tres por ciento», no se ha quedado atrás con un 3,3 por 100 en noviembre del 2000, lo que representó su mayor incremento en los últimos nueve años. No solamente, pues, se ha superado en los precios la barrera del 3 por 100 «de entrada», sino además el objetivo del 2 por 100 de inflación fijado para el año 2000, mientras el precio del dinero a finales de 1999 estaba en el 2,5 por 100 y a finales del año 2000 se situó en el 4,25 por 100 con tendencia ascendente (el BSCH hizo en septiembre del 2000 una previsión de hasta un 5 por 100 en los tipos de interés para el año 2001 con tendencia al alza). Los indicadores reflejaban que la inflación se había descontrolado sustancialmente (petróleo aparte) porque la economía de la UE ha crecido sin contener la demanda interna. Al contrario que Estados Unidos, cuya economía ha sido capaz de crecer a elevadas tasas (5,3 por 100) sin tensiones inflacionistas, al menos hasta el frenazo de finales del 2000. Es cierto que los altos precios del crudo (se encarecieron un 29,3 por 100 en un año) influyeron en Europa, pero también dispararon el déficit comercial de Estados Unidos y su impacto, aunque hayan derivado a la baja, coyunturalmente entrañará siempre riesgos para la economía global, en un mundo en el que, por diversas razones, que exigirían un prolongado análisis, no terminan de implantarse energías alternativas.

Mediando esta o cualquier otra razonada explicación, el resultado es que el euro se llegó a depreciar hasta un 29 por 100 desde su estreno en enero de 1999, y no parece que sólo un endurecimiento de la política monetaria centralizada mejoraría la situación, sino incluso al contrario (en palabras de Ken Landon, analista del Deutche Bank), como se demostró tras las sucesivas intervenciones del BCE a lo largo del agobiante otoño del 2000. Lo que pudiera frenar las perspectivas de recuperación duradera en Europa son las dudas sobre la propia marcha de Alemania, cuya economía, la mayor de la UE, presenta señales de ralentización, habiendo llegado a registrar por primera vez incremento del desempleo. El hecho es que a finales del año 2000 habían fluido considerables sumas de dinero desde Europa hacia Norteamérica y el temor es que, si en un futuro previsible las inversiones siguieran viajando, pese a todo, hacia Estados Unidos, el dólar sería inexorablemente más fuerte que el euro de manera sostenida. Hipótesis que parece tiende a desdibujarse últimamente a causa de la coyuntura americana. 
Pero aunque se produzcan recuperaciones esporádicas del euro, los expertos siguen teniendo serias dificultades en contraponer remedios para mantener estable de manera prolongada la moneda única, que se ha revelado excesivamente dependiente. Sin embargo, analistas como Sachs (director del Instituto Harvard para el Desarrollo Internacional) ha previsto en diciembre del 2000 un brusco aterrizaje para el 2001 de la economía norteamericana con crecimiento del 1 por 100 e incluso cero, mientras vaticina que la economía europea seguirá creciendo al 3 por 100 y el euro recuperará su paridad con el dólar, regresando a Europa muchas de las inversiones que han viajado a Estados Unidos. Vaticinio al que parece quería aproximarse la realidad en enero del presente año en lo que se refiere al crecimiento europeo (superó el 3 por 100 de media, aunque luego sufriera un sensible retroceso), pero no tanto respecto a la espinosa recuperación de la moneda. Queda por comprobar el determinante alcance y perfiles de la crisis económica estadounidense. Queda por comprobar también el horizonte de la desaceleración europea, así como la que apunta Japón. Y los vaticinios en el escenario actual es fácil que deparen un resultado tan erróneo como errático.

\section{A propósito de la Reserva Federal}

Precisamente a tenor de esta interrelación euro-dólar, sí parece oportuno detenerse a reflexionar sobre el modelo económico de la Reserva Federal al que Europa muestra querer imitar y al que desde luego tan de cerca observa tanto en la etapa de bonanza como en la de enfriamiento posterior. Es un dato que la economía americana creció sostenidamente y sin recalentamiento porque, entre otras cosas, además de la cautelosa política de Greenspan al frente de la Fed, los ciudadanos estadounidenses sólo solían derrochar lo suficiente como para mantener estables los precios, mientras el deflactor del PIB estaba y está vigilado muy de cerca por el Banco Central de Estados Unidos. Era tanto así que hasta hace poco la buena salud de la primera economía del mundo se ha debido más a la elevada inversión de las empresas que al consumo de los ciudadanos (éste sólo había crecido un 2,9 por 100 a finales del 2000). La explicación más consistente estriba en una contrastada productividad empresarial, consecuencia de una probada eficiencia basada en la fuerte inversión en infraestructuras, equipos informáticos y alta tecnología. En esa línea, la economía norteamericana ha mantenido diez años de bonanza ininterrumpida y alcanzó el punto más alto de inflexión a mediados del año 2000. Luego se constató un sensible aminoramiento en esta imparable marcha, aunque un sector de expertos ha pre- visto que los efectos de la más larga etapa de prosperidad económica estadounidense pudieran seguir perdurando a pesar de coyunturales bajas y de la confusa situación a principios del 2001, pues las empresas continuarían optimizando sus recursos. La «pócima secreta» que permitió un fuerte crecimiento con tasas moderadas de inflación y bajo desempleo ha sido una sólida productividad apoyada en la gran flexibilidad del mercado laboral y la inversión tecnológica. Poco que ver con la Unión Europea, donde el crecimiento ha arrastrado en general a los precios. Y la posible utilización en Europa de la política fiscal como instrumento de contención, incrementando hipotéticamente la presión impositiva, podría suavizar un consumo desenfrenado moderando la demanda, pero genera serias dudas respecto a su efecto en otros indicadores. Porque, aunque pudiera funcionar a corto plazo, a largo es probable que generara mayor gasto público. Además, depende del momento del ciclo en que se aplique una y otra política fiscal. En España se redujo la presión en un momento de crecimiento y expansión, lo que originó excesivo optimismo en el bolsillo de los consumidores (ya contenido), mientras que en Alemania, por ejemplo, se aplicó dicha reducción en un momento de desaceleración. En cualquier caso, una mayor presión impositiva, aunque modere la demanda, resultaría a todas luces impopular políticamente, y parece claro que las medidas no apuntan en esa dirección. $\mathrm{Ni}$ en Europa ni en Estados Unidos, donde se ha producido un recorte fiscal moderado como motor de reactivación económica, propuesto políticamente por el nuevo Presidente, pero respaldado por la Reserva Federal sobre la base de que el superávit presupuestario ha permitido la medida, «al menos por el momento", en los ya tradicionalmente cautelosos términos de Greenspan. Lo cierto es que a enero del 2001 la situación económica norteamericana era un tanto desconcertante con tendencias contradictorias en los diversos indicadores que han dificultado conocer tanto las previsiones como sus posibles impactos. Cuesta, no obstante, aventurar que la desaceleración desembocará o que la dejarán desembocar en una seria recesión, a pesar de la primeras señales de alarma en indicadores como el paro.

Parecía que la Reserva Federal tenía las manos atadas para aplicar sucesivas bajadas de tipos, mientras daba la impresión de que lo que hiciera o declarara Greenspan ya pudiera afectar menos a los inversores globales. Otra errónea impresión. También se ha aplicado a la situación americana el término «estanflacción», lo que en realidad todavía es inadecuado. Porque dicha expresión denomina en puridad una situación en la que se produzca inflación de dos dígitos (en el 2000 fue del 3,4 por 100) junto con un desempleo similar, y éste no es aún el caso americano. La explicación no está clara, pero puede tener bastante que decir al respecto el fin de la euforia financiera en los valores tecnológicos. Los analistas utilizan nuevos métodos de valoración para la nueva economía, pero sigue sin haber un método riguroso que sea capaz de dar firmemente con el 
fondo de la cuestión, y los mercados de renta variable no son el reflejo de lo que sucede, sino el problema, pues los valores tradicionales tienden a mantenerse, mientras el bajón de la euforia reciente en la «economía digital» puede arrastrar a la economía real. De momento, el recorte de impuestos sigue siendo la medida por excelencia propuesta por la nueva administración americana (sin dejar de lado las bajadas de tipo), sobre todo al contar con un superávit presupuestario que se puede calcular en 5,6 billones de dólares a lo largo de la década. Este breve apunte viene a introducir una situación que se analizará a propósito de otras cuestiones.

\section{A propósito del caso danés}

En otro orden de cosas, el reciente incierto ciclo que tanto ha maltratado al euro produjo indudables reticencias entre los candidatos inmediatos al ingreso en el club de los hoy ya Doce. Ha sido el caso de Dinamarca, quien mostró y ha mantenido desde el principio una contradictoria relación con la UE. La mayoría de los daneses creen vivir en el mejor de los países posibles. Su moneda, la corona, estaba vinculada al marco alemán en su cotización y se consideró que, consecuentemente, lo estaría al euro. En esa convicción el primer ministro danés procedió a convocar el fracasado referéndum de entrada. Pero el resultado negativo no ha ido dirigido contra la pérdida de la autonomía monetaria danesa, ni siquiera contra la moneda única, sino que late en la mayoría de la población el temor a un «matrimonio forzoso» con países a los que consideran menos ricos, menos formados y más dependientes. Y los daneses, desde dicha sensibilidad, manifestaron un no tan mayoritario que puede calificarse de rotundo. Una negativa que se ha denominado un tanto dramáticamente victoria del miedo, pero en realidad responde a una psicología colectiva que no desea embarcar en un avión muy acompañados, pero no perciben si bien acompañados y tampoco la certeza de dónde va a aterrizar. Parece no atraerles lo que denominan abiertamente la Europa de los mercaderes. También alguna ortodoxia de corte «patriótico», ya mencionada, ha interpretado ese no como triunfo del nacionalismo frente al internacionalismo, mundialización o globalización. Los datos revelan que la economía danesa constituye sólo menos del 3 por 100 del PIB de la actual zona euro, por lo que desde esa perspectiva el impacto cuantitativo del no sería irrelevante. Además, el no danés también puede significar únicamente un compás de espera que bien pudiera modificarse cuando el euro deje de ser moneda virtual a partir de enero del 2002. Lo que sí parece probable es que el más incisivo impacto de este resultado se plasme en la reacción del Reino Unido ante su hipotético y muy particular referéndum de entrada. Hipotético y particular porque, al ganar los laboralistas las elecciones en 1997, Blair prometió la celebración de un referéndum de entrada en el euro cuando se cumplieran una serie de objetivos fijados entonces por su gobierno, algunos de los cuales aún no se han cumplido y para los que se ha establecido un plazo de al menos dos años. Pero el motivo de la dilación no es tanto dicho cumplimiento como que en realidad Blair «vende poco euro» a una sociedad que se siente satisfecha con su economía y su divisa, habiéndose incluso manifestado mayo. ritariamente en contra de la moneda única cuando las encuestas pronostican un segundo triunfo laborista consecutivo tras cien años sin producirse; pronóstico que parece viene apoyado no tanto en la tambaleante popularidad de su líder como en el «bundimiento» del partido conservador. No obstante, queda por ver el impacto electoral efectivo del presente agobio que acosa al gobierno laborista. Lo que sí parece indudable ha sido un efecto en cadena de debilidad del euro, negativa danesa, crecimiento posterior del «euroescepticismo», a pesar del mensaje inmediato de los países de la zona UEM en cuanto a que la ausencia de la corona danesa no iba a alterar la solidez de la moneda europea (Ecofin y BCE). A su vez, la pronta reacción del Banco Central de Dinamarca tras el no, consistía en subir los tipos de interés medio punto (un 5,6 por 100); medida de endurecimiento monetario que justificó como necesidad de apoyar la moneda nacional frente a presiones y evitar incertidumbres. Los máximos responsables monetarios de la UE se apresuraban a comunicar que la negativa danesa no iba a alterar ni el calendario de reforma del Tratado de Amsterdam ni el de la ampliación a la Europa del Este (Niza, diciembre del 2000); y así ha sido. Otro efecto previsible, además del británico, puede ser el impacto en la opinión pública sueca, país que retrasaría su consulta de entrada probablemente al año 2003 o 2004.

En cualquier caso, tras el referéndum danés y tras la cumbre de Niza, la Europa de distintas velocidades parece instalada y la futura construcción europea ha de plantearse ya claramente conscientes de que no todos los socios quieren jugar a lo mismo. Podrían quedar sólidamente establecidos dos círculos concéntricos de países miembros resucitando aquella distinción siempre latente de Pequeños y Grandes Europeos. Dinamarca en cierto modo ha clarificado lo que en realidad es Europa, y Niza en alguna medida lo ha confirmado. Como también puede interpretarse el no danés, sería a modo de llamada a que se ralentice el tren de la prevista integración-ampliación europea. Pero en todo caso resultó una inoportuna «euronegativa» por lo delicado del momento y ha dado lugar a múltiples lecturas. Resultaría interesante pronosticar si alguna de ellas tendrá que ver con el próximo referéndum suizo respecto a iniciar negociaciones para su adhesión a la UE prevista a finales de esta década (Suiza presentó su candidatura en 1992, que fue inmediatamente congelada por el pueblo en aplicación de su sistema de democracia directa). 


\section{A propósito de la globalización}

Reflexionar a propósito del euro obliga a efectuar también algunas consideraciones sobre la globalización económica. La multitudinaria protesta de diferentes colectivos en la plaza Wenceslas de Praga (septiembre del 2000) frente a los representantes del Fondo Monetario Internacional y del Banco Mundial reunidos en su 55 Asamblea, pretendía acabar con el orden económico impuesto por la globalización, entendido como una lucha contra el sistema económico neoliberal de cuyos desmanes responsabilizan también a la Organización Mundial del Comercio. Los argumentos esgrimidos por estos grupos se centran en que el crecimiento producido como consecuencia de la liberalización mundial del comercio es destructivo en sí mismo, dado que los puestos de trabajo que crea son más precarios y que cuando una economía débil entra en el sistema global, se vuelve absolutamente dependiente y vulnerable ante los vaivenes del capital internacional, hasta el punto de que la injusta distribución del crecimiento económico en dichos países intensifica las tensiones políticas promoviendo, a la postre, la represión. Pretenden que se condonen o desaparezcan las deudas de los países pobres. $Y$ algunos de estos grupos abogan, como mal menor, por una globalización cuyo motor sea la ONU, no los agentes económicos. En realidad, el BM y FMI se fundaron tras la Segunda Guerra Mundial para ayudar a la reconstrucción de Europa y, ciertamente, en los últimos años sus competencias se han ido extendiendo, llegando a prestar en la actualidad hasta 30.000 millones de dólares al año a los países pobres. El propósito fundacional del FMI consistía en efectuar préstamos a corto plazo para estabilizar las monedas locales, y hoy hace efectivos préstamos a largo plazo e impone planes de austeridad a los países menos favorecidos. Los escuetos datos, sin mediar juicios de valor, revelan que más de cincuenta países soportan deudas que nunca podrán sufragar, derivando un elevado coste para sus poblaciones, y que más de noventa países están sujetos a los programas de austeridad del Fondo, lo que obliga a sus gobiernos a recortar gastos drásticamente en todo tipo de servicios básicos para la población, reduciendo barreras de tal manera que industrias, tierras y activos terminan en manos extranjeras. Otra cuestión es cómo y por quién se utilicen estos datos. Con independencia de la evolución en las actividades de las tres instituciones (FMI, BM y OMC) y sus derivaciones desde los propósitos iniciales, se puede percibir que, tras la 55 Asamblea de Praga, se ha producido un cambio cualitativo en el sentido de intentar acercarse, al menos declarativamente, a los planteamientos de los grupos contestatarios y de haber admitido los propios dirigentes de las mismas que, sin dar marcha atrás en la globalización, se pudiera, no obstante, intentar reconvertir dicho proceso en un instrumento de oportunidades y no de inseguridad y hasta de miedo. Algo, pues, está cambiando al menos formalmente tras Seattle y Praga, que parece confirmado en Davos (enero del 2001) si se atiende a las declaraciones de los máximos dirigentes financieros mundiales como producto de la reflexión interna en las propias instituciones que lideran.

El próximo relevo en la cúpula directiva del FMI (Fischer, Camdessus, Mussa), que vivieron de forma protagonista las crisis globales de 1997 y 1998 (fracasos de Indonesia, Corea, Rusia y Brasil), pudiera significar un repunte en la credibilidad de la institución, sobre todo tras la crisis de Turquía y Argentina tan deficientemente manejadas. Se está produciendo la apariencia de que el Fondo ha aprendido de sus errores o al menos los reconoce retóricamente. Falta que ese reconocimiento pueda convertirse en políticas activas, sobre todo para paliar los desequilibrios y grietas producidad por la liberalización del mercado de capitales basada en el criterio de que produciría un crecimiento más rápido en los países menos favorecidos, sin tener ninguna evidencia contrastada de ello. Probablemente bastaría con aplicar el concepto de que la economía es la utilización de evidencias y de pruebas irrefutables disponibles y de teorías de probado funcionamiento.

No cuesta excesivamente admitir el argumento de que el problema de fondo reside en que la mundialización, y más concretamente la globalización financiera, no son sólo consecuencia de una casuística económico-tecnológica, sino que en buena medida obedecen a una serie de decisiones cuyo propósito fue, y sigue siendo, crear un espacio único por el que circulen, sin o con muy pocas limitaciones, bienes, servicios y, sobre todo, dinero, que se convierte en la mercancía por excelencia. Los analistas críticos convienen que en dicho espacio global convergen los intereses de empresas transnacionales, quienes son en realidad sus principales impulsores y beneficiarios y que van acompañadas por las políticas económicas de Estados Unidos y los grandes Estados del Norte, añadiendo que sus principales instrumentos están constituidos por la ideología ultra o neoliberal y por organismos como el FMI, BM, OMC, $\mathrm{OCDE}$, etc., sin un marco jurídico definido que regule e incluso controle su funcionamiento. Así, según estas teorías, acumulación de capital y creación de riqueza se disocian, primando en múltiples ocasiones la especulación sobre la inversión. Recurriendo de nuevo a los datos, si el crecimiento mundial medio de 1999 puede establecerse en el 3,5 por 100 no es apocalíptico ni tendencioso constatar que en y desde ese año se ha incrementado la concentración de la riqueza, se ha fomentado la creación de oligopolios, se han agravado las desigualdades, y la miseria y el hambre se han instalado endémicamente en determinadas zonas del planeta. Para ciertas corrientes de pensamiento, reconducir las desviaciones de este proceso no parece indicado que deba corresponder a las protestas antiglobalización, sino que lo útil sería intentarlo desde dentro, y en dicho sentido algunos analistas apuntan como vía la creación de macroáreas regionales, señalando a la UE como experiencia 
más lograda a pesar de sus dificultades. Así, ASEAN y Mercosur, correctamente regulados, podrían también dar juego en dicho sentido, siempre según esta línea de pensamiento.

La reunión en Davos (Suiza, enero del 2001) del Foro Económico Mundial ha puesto decididamente sobre el tapete las fisuras de la globalización. Lo cierto es que hay una crisis de modelo, pues ya no vale el de 1999 con Estados Unidos como locomotora económica mundial, ni el del 2000 que proclamaba el fin de los ciclos y el triunfo de la era Internet. En el 2001 se ha descubierto que la nueva economía tiene también ciclos, aunque sean distintos, y que el fracaso de buen número de negocios en Internet abre una «brecha digital» acompañada por la precipitadamente calificada recesión americana, aunque se siga confiando, ya no tan ciegamente, en las capacidades casi mágicas de Greenspan. No obstante, en Davos se volvió a reiterar que la globalización, a pesar de todo, sirve, y que no hay que salirse de ella, sino reconducirla desde dentro, en la línea anunciada por los dirigentes financieros mundiales tras la reunión de Praga. Precisamente Davos (que se celebra desde 1971) merece aquí una consideración un poco más detenida, pues en la última década del siglo xx las reuniones del Foro Económico Mundial se habían convertido en un símbolo del triunfo del capitalismo planetario, y a comienzos del siglo XXI han dado en convertirse en un núcleo de cierta reacción contra ese capitalismo hasta el punto de haberse hablado de «la cuestión de Davos». En la ciudad suiza se ha planteado abiertamente lo que asomó en Seattle y Praga: la asimilación de la protesta en lo que se refiere al equilibrio entre seguridad, libertad y diálogo, y la posibilidad de asumir desde dentro los criterios de los contestatarios, reconduciéndolos. El planteamiento y el reto consiste en si se puede erigir un sistema económico diferente tras los sucesivos fracasos por conseguirlo. Y Davos 2001 se ha debatido entre intentar erigirse en el foro donde dialoguen poderosos y desposeídos o donde los ricos se reúnan para incrementar su riqueza, dejando transcurrir libremente las fuerzas en juego.

En el otro lado, la reunión de Porto Alegre por primera vez ha sido un contrapunto de Davos y, de paso, también de Praga y Seattle. La conferencia del Foro Social Mundial a finales de enero del 2001 ha representado una alternativa a la antiglobalización, contraponiendo la posibilidad de otra globalización distinta como superación de los planteamientos de rechazo total a cualquier globalización que viene sustantivándose a través de la protesta como única vía. Se trata de construir alternativas económicas, fortalecer alianzas Norte-Sur y formular propuestas realmente operativas para democratizar y reconducir las actividades de la OMC, FMI y BM, analizar el papel de las multinacionales $y$, en fin, propiciar el desarrollo sostenido. El tiempo dirá si las opiniones de Porto Alegre serán tan parciales como las de Davos, aunque en otra dirección. Pero en cualquier caso dejar constancia aquí de ambas reuniones, simul- táneas en el tiempo, viene a corroborar que la globalización parece se está autoexaminando, mientras la antiglobalización parece tiende a buscar alternativas al catastrofismo, aunque alrededor de dicho objetivo de protesta se están aglutinando diferentes colectivos que en forma violenta manifiestan su oposición a otras cuestiones de las que responsabilizan a la globalización.

Pasaron ya los días del entusiasmo mundializador y globalizador. Ahora se está viendo que el principal punto débil de la globalización es precisamente que ha resultado poco global. Es decir, que sus componentes (nuevas tecnologías, new economy neoliberal, penetración intercultural y sociedad de la información) sólo alcanza al 15 por 100 de la población mundial. La pobreza sí es más global y el propio Camdessus (FMI) ha reconocido que ella podría hacer saltar el sistema. Quizás el principio de la solución se encuentre en sustituir al mercado como único protagonista que depara beneficios sólo unilaterales, por la interpenetración de la cultura y el conocimiento que permita emerger al 65 por 100 de la población mundial marginada de sus beneficios, y además emerger en sus espacios vitales sin emprender huidas desesperadas, masivas y descontroladas (excepto por las mafias organizadas) hacia las zonas privilegiadas del planeta generando, lejos de un indicio de solución, un nuevo y nada desdeñable problema.

Por último, resulta obligado, antes de cuestionarse nuevas reflexiones, aludir en este punto a la denominada tasa Tobin. Efectivamente, el premio Nobel de economía James Tobin propuso hace más de veinticinco años un impuesto que gravara los movimientos especulativos de divisas y que esa recaudación fuera a parar a los países más pobres del planeta. Se trataba de una tasa fiscal de pequeña cuantía $(0,5$ por 100$)$ sobre cada movimiento transfronterizo de capital como remedio antiespeculativo, amortiguando así las fluctuaciones de los tipos de cambio y disuadiendo a los especuladores. Aquél era un mundo bien diferente al actual (año 1971) en el que Estados Unidos abandonaba el sistema Bretton Woods de tipos de cambio fijos y se iniciaba el fenómeno de las transacciones electrónicas de dinero, lo que multiplicaba gigantescamente el número de las mismas. Y Tobin, como declarado discípulo de Keynes, se basó en su Teoría general del empleo, interés y dinero (Capítulo XII) con la idea de aminorar los efectos perversos de ese imparable proceso. La oportunidad de detenerse aquí en una breve mención a la tasa Tobin obedece a haber sido «resucitada» por los movimientos antiglobalización (por ejemplo, el grupo Attac) y porque los gobiernos de la Unión Europea, sobre todo los grupos socialistas, aunque con discrepancias entre ellos, se plantean debatirla incluso en el seno del Ecofin. Los problemas estriban, como indicó el propio Tobin, en que el impulso de la tasa tendría que ser mundial, habría que definir cuáles de los movimientos de divisas y capitales son realmente especulativos, y contar con instrumentos operativos e instituciones que respalden la medida y eviten de manera efectiva la huida de 
capitales a los paraísos fiscales, reduciendo las asimetrías que ha producido la globalización.

\section{A propósito de la ampliación de la UE}

Volviendo a reflexionar sobre el inmediato futuro de Europa, la ampliación de la UE puede complicar el panorama interno no sólo organizativamente, sino como futuro espacio del euro. Ya está anunciada formalmente la adhesión de la República Checa, Eslovenia, Estonia, Hungría, Polonia y Chipre, precisamente durante los años que el euro se inicie como moneda corriente, en una línea de aproximación al Este marcada por la política exterior alemana, cuya propia agenda se convierte con excesiva frecuencia en la comunitaria. La UE se ha comprometido no sólo a aceptar, sino a acelerar esta ampliación que, ya se ha indicado, convertirá los quince en dieciocho muy pronto, y no tan lejos en veintisiete, ligando moneda única y ampliación a modo de un objetivo-atracción que puede implicar cierto riesgo para el equilibrio comunitario en cuanto se refiere al voto ponderado de los Estados, a los criterios de los fondos estructurales y de cohesión o a la Política Agraria Común. Es verdad que Europa occidental arrastra una deuda con sus vecinos del Este, pero lo más acertado parece intentar ser cuidadosos con los plazos y cohesionar sólidamente la Unión - no sólo la monetaria - antes de ampliarla. Esto es lo que el Tratado de Niza intentará posibilitar, como paso previo imprescindible para la ampliación hacia el Este y la extensión de la zona euro. Los analistas se referían antes de Niza a la necesidad de reformar sólo los «flecos» de Amsterdam, pero en realidad se estaban abordando asuntos tan delicados que imposibilitaron un acuerdo en 1997, dejando sin resolver cuestiones como la ponderación del voto en el Consejo o la reforma de la Comisión, así como la extensión del voto por mayoría cualificada para ir reduciendo el derecho de veto. Posteriormente se añadió el espinoso asunto de flexibilizar las cooperaciones reforzadas y la actualización de los mecanismos comunitarios para hacer frente a crisis como la provocada por el acceso al poder de la extrema derecha en Austria (art. 7 del Tratado). La cuestión de los votos en el Consejo, por seleccionar un ejemplo, no deja de ser un reflejo del desequilibrio que han conllevado las sucesivas ampliaciones. Y es que la primigenia UE fue fundada por seis países, de los que tres eran grandes (Francia, Alemania e Italia) y. tres pequeños (Bélgica, Holanda y Luxemburgo), y los votos han tenido siempre una indudable relación con el tamaño de la población de los Estados miembros, aunque se afirme reiteradamente que no es una transposición matemática del mismo. De los actuales Quince, demográficamente cinco son grandes (incluida España) y diez pequeños o medianos, y este desequilibrio se va a acrecentar con la ampliación al Este, pues al margen de Turquía, que es caso aparte, entre los futuros socios sólo hay un país grande (Polonia) y otro mediano (Rumania) frente a países no sólo pequeños, sino minúsculos (Bulgaria, Hungría, República Checa, Eslovaquia, Eslovenia, Estonia, Letonia, Lituania, Chipre y Malta). Si los pequeños desconfían respecto a dejar demasiado poder a los grandes, también éstos desconfían entre sí porque el país más beneficiado sería (y ha sido) Alemania, al fin y al cabo la primera economía y el país más poblado de la UE. En dicho mosaico de intereses, las cooperaciones reforzadas se erigen en el mecanismo que posibilita a un grupo de países avanzar en la integración europea sin obligar a los más reticentes a seguir el mismo camino, lo que conduce a una Europa a dos o varias velocidades; algo, al fin y al cabo, similar a lo que se hizo con la unión monetaria y con los acuerdos de libre circulación de Schengen. Y el no danés al euro vino a dar fuerza añadida a los países partidarios de facilitar la Europa de distintas velocidades. En el actual panorama de círculos concéntricos y de Grandes y Pequeños Europeos, con vistas a la futura ampliación el término clave, más que integración, va a ser el de equilibrio.

Con ese incierto horizonte el ministro de Exteriores alemán Fischer salió al paso de la posible hegemonía práctica de Alemania proponiendo la expresión «Unión de Europa» frente a la de «ampliación». Un probable eufemismo, porque en Niza, según la opinión de algunos analistas, parece haberse gestado un híbrido entre lo intergubernamental y lo federal, modelo este que en las últimas etapas de la unificación europea ha vuelto a planear como futuro organizativo. En cuanto a la psicología colectiva española, no estando en contra de la ampliación desde el punto de vista político, teme, sin embargo, sus costes económicos, que percibe como perjudiciales no sólo por el desvio de los fondos de cohesión, sino también probable mente como consecuencia de la secular postura de España «de espaldas» al este de Europa. Pero países como Polonia, Hungría y la República Checa suman más de 60 millones de habitantes, cuyas preferencias de consumo puede resultar que estén más cerca de las de los españoles que de las de otros países europeos con mayor desarrollo. Aunque bien pudiera suceder, como tantas otras veces, que el mayor impacto positivo se produzca en sectores que nadie o muy pocos hubieran imaginado. La cumbre de Niza ha tenido la clave de cómo va a funcionar el marco institucional en el que circulará el euro. Hubert Vedrine, ministro de Exteriores francés, ya se refirió con anterioridad a su celebración a la necesidad incluso de redactar un nuevo Tratado de la Unión que sentara las bases para acoger nuevos miembros en el año 2003 y sucesivamente hasta treinta países. Pero advirtió también que si se ampliara la Comisión al ritmo de las nuevas adhesiones no podría funcionar como órgano colegiado, pudiéndose llegar al bloqueo funcional. Niza ha producido, pese a todo, un cierto aliento positivo en los aspirantes a integrarse 
en una UE cuya marcha económica, aunque frenada, no es negativa en términos globales, sobre todo en lo que se refiere al crecimiento e incluso con previsiones optimistas, aunque medien las lógicas y fundamentadas reservas. Sin embargo, se está instalando un «euroescepticismo» que combina reveses económicos con dificultades políticas frente a la cada vez más percibida como necesaria reforma previa efectiva de la Unión Europea. La grave injerencia de un problema tan específico como el ganadero-alimentario (encefalopatía espongiforme bovina) ha venido a desnudar de nuevo determinadas realidades internas, dejando patente el enfrentamiento París-Berlín por el futuro de la Política Agraria Común (para Francia, la PAC es válida, mientras que Alemania insiste en una revisión profunda sobre la gestión de las subvenciones agrícolas), lo que entorpece las propuestas de la Comisión, que se considera no sólo competente, sino obligada a intervenir. En definitiva, la ampliación está haciendo aflorar una serie de tensiones internas todavía por resolver, al tiempo que aporta notables incógnitas sobre la forma menos convulsiva de asumir a unos países que, ellos sí, están sufriendo todavía las traumáticas consecuencias de su recientísimo pasado. No sólo hay divergencias entre los gobiernos de los Estados miembros, sino dudas razonables en la psicología colectiva de algunas de sus poblaciones, que pudieran deparar sorpresas.

\section{A propósito de la crisis petrolífera del 2000}

Abundando en el «euroescepticismo», la elevación del precio del petróleo ha sido un detonante que desnudó también algunas realidades semiocultas por el «euroidealismo». La subida del precio de los carburantes en el otoño del año 2000, al tiempo que sacó a la calle una escalada de protestas, puso de manifiesto, sobre todo, dos cuestiones. Una, la ya expuesta falta de coordinación de las políticas no sólo de los entonces todavía Once (faltaba Grecia en los UEM), sino también de los Quince, y otra, la escasa influencia de la UE como entidad unitaria ante los países exportadores de petróleo a fin de que mantuvieran la producción de crudo en los niveles necesarios para su demanda y la estabilidad del mercado. Mientras los ministros de Economía y Finanzas de la UE desaconsejaban rebajas en la fiscalidad de los carburantes, Italia se desmarcaba del consejo del Ecofin y rebajaba, vía impuestos, el precio del gasóleo para frenar el caos que observaba en sus socios (luego Francia y Bélgica aplicaron una política fiscal propia). Saltaron a la vista de nuevo los problemas de coordinación internos a través de las actuaciones individualizadas de Italia, Bélgica y Francia, mientras España, Reino Unido, Irlanda, Alemania y Países Bajos se negaban a revisar la presión fiscal sobre los carburantes. Tampoco hubo acuerdo en cuanto a actuar conjuntamente Estados Unidos y la UE ante la OPEC, pues en semejante coyuntura Estados Unidos prefirió negociar unilateralmente. A su vez, los once países exportadores de petróleo anunciaron «tímidamente» que volverían a incrementar la cuota de producción de crudo si fuera «estrictamente necesario», tras haberla subido tres veces a lo largo del año 2000, hasta 32 millones de barriles diarios. El secretario general de la OPEC advertía al G-7 que no utilizara a su organización como exclusivo causante del malestar de los consumidores y de las consiguientes movilizaciones, criticando la actuación unilateral de Estados Unidos al sacar 30 millones de barriles de sus reservas estratégicas de crudo a fin de contener los precios. Medida vía reservas que casi ningún país de la UE está en condiciones de aplicar, empezando por España, quien cuenta con unas reservas que garantizarían el consumo de unos noventa días, o incluso Alemania, cuyo ministro de Finanzas llegó a declarar que «carecian de ellas» (una realidad debida a la estructura de los depósitos). Además, las reservas de la UE tienen una finalidad estratégica en prevención de desabastecimiento, y en ningún caso para corregir los precios del mercado, por lo que, en puridad, su utilización a tal fin constituiría una perversión del objetivo para el que fueron constituidas y equivaldría a una intervención arbitraria en el mercado. Aparte de que si los precios bajaran por esa vía, habrían de reponerse las reservas y tal reposición provocaría tensiones en el mercado con un consiguiente nuevo ascenso del precio del petróleo. Sólo parecería justificable una intervención de este orden si se contemplara la hipótesis de que los precios cayeran sensiblemente en breve plazo, por lo que, entonces, recomprar más barato podría resultar rentable. Tras la bajada del crudo a finales del año 2000 se ha especulado que a mediados de 2001 el barril pudiera costar una media de 26 dólares, pero también se vislumbra que la demanda global seguirá creciendo con el consecuente efecto arrastre. De todas maneras hubiera parecido razonable que una intervención vía reservas se hubiese articulado de forma concertada entre Estados Unidos, Japón y la UE a través de la Agencia Internacional de la Energía. El problema de Europa se manifiesta a propósito de la energía, una vez más, muy distinto al de Estados Unidos. Aparte la consideración de su inferioridad de reservas reales respecto a Estados Unidos o Japón, la cuestión vuelve a ser de consenso entre sus miembros y la diferente estructura de los depósitos (en Alemania, por ejemplo, todas las reservas están en depósitos privados), ante lo cual la actitud de la Comisión se refugiaba en la prudencia de no proponer una medida que no se aprobara o que no surtiera ningún efecto en los mercados. Entre tanto, los países productores amenazaron con recortar la producción si el precio del petróleo se desplomaba por esta vía, y se llegaron a alcanzar los 35 dólares por barril.

Haciendo memoria, la OPEP (también OPEC) en sus cuarenta años de historia ha atravesado tres momentos convulsivos: 
uno en 1973-1974, a raíz del embargo petrolero a los aliados de Israel en la guerra con los árabes; otro en 1979-1981, tras la revolución iraní y la guerra Irán-Irak, y el tercero en 1990-1991, a raíz de la invasión de Irak a Kuwait. Pero la crisis de noviembre del 2000 por primera vez no tuvo un trasfondo bélico (el enfrentamiento palestino-israelí se acumuló después), sino que obedecía a criterios puramente políticos y económicos. La creciente demanda mundial y las políticas de beneficios de las grandes compañías petroliferas, añadida la fiscalidad específica de cada país industrializado, sin olvidar la peculiar actitud de la OPEC, dispararon los precios y amenazaron con derrumbar los logros de crecimiento tanto de Europa como de los países en vías de desarrollo. Incluso para Estados Unidos podría haber significado un plus para el principio del fin de una década de crecimiento sostenido. El factor político de la crisis energética se agravó con la presión que Estados Unidos, la UE y el G-7 ejercieron sobre la OPEC. De todos modos, aunque el impacto del precio del crudo en la inflación europea ha sido indudable, no toda la inflación deriva de la factura del petróleo. Para los países importadores la elevación del precio del crudo tiene al menos dos efectos inmediatos: una transferencia de rentas hacia los países productores y una elevación de los costes internos de producción y del nivel general de precios. En consecuencia, se deriva un real «empobrecimiento» de las economías afectadas situando a Europa (y España) en una posición más comprometida respecto a otras economías desarrolladas menos dependientes energéticamente (para España ha podido suponer al menos un punto adicional sobre el incremento de los precios de consumo). Pero, además, el incremento de los precios del crudo también se vio afectado por la crisis de Oriente Próximo en el mes de noviembre que disparó el precio hasta 35,30 dólares el barril, el más elevado desde 1990 (guerra del Golfo), cuando por añadidura el invierno en el hemisferio norte incrementaba la demanda y las existencias de los paises industrializados habían disminuido sensiblemente, según fuentes de la Agencia Internacional de Energía y el Instituto Americano del Petróleo, en una espiral que el mercado, y sólo el mercado, se mostraba incapaz de reconducir. La reunión en Riad entre la OPEC y los principales países importadores en el seno del Foro Internacional de la Energía (creado en 1991) no añadió perspectivas de solución, habida cuenta el enconamiento de las acusaciones mutuas en cuanto a superponer sus propios intereses a los de los usuarios. Tras el descenso de precios a principios del 2001, los países productores han vuelto a plantearse reducir la producción, lo que puede emplazar a Europa ante otro incierto ciclo. En todo caso, reflexionar a propósito del euro conduce a una parada obligatoria para efectuar una breve consideración sobre un problema con enorme capacidad de convulsionar los mercados, las cotizaciones de divisas y el decisivo indicador que es la inflación para la marcha de cualquier economía.

\section{A propósito de la cumbre de Niza}

En dicho agitado escenario los gobernantes europeos parecían incapaces de transmitir claros mensajes sobre la reforma y ampliación de la UE o dónde iba a encontrar estabilidad la moneda única, mientras el referéndum danés se planteó en un delicado momento, y sólo un 20 por 100 de los británicos se decantaban a favor de la desaparición de la libra esterlina (Eurobarómetro 2000), aunque su continua revalorización dañara las exportaciones. La celebración de un posible referéndum en el Reino Unido para la entrada en el club de los Doce ya se ha mencionado que no se vislumbra de manera inmediata, y el resultado danés sin duda ha actuado también como laboratorio ante los países que se planteen incorporarse a la moneda única, abriendo además la vía de celebrar referéndums sobre otras cuestiones de fondo que tiene pendientes la UE. La realidad es que en un momento en que Europa afrontaba el reto de asumir casi el duplicar sus miembros y definir la puesta en práctica de su futuro político y económico, los ciudadanos no percibían claramente la meta ni el camino hacia ella, y subsisten aún fundadas incertidumbres sobre las perspectivas económicas y el impacto de la más que probable corriente inmigratoria que reportaría la entrada (Eurobarómetro 2000) de los doce países que están negociando su incorporación, además de Turquía que tiene categoría de aspirante a candidato soportando una brutal crisis que el FMI intenta con dudosas medidas que no se extienda ni en el tiempo ni en el espacio. $Y$ es que las posturas de los líderes europeos respecto a la configuración de Europa siempre han diferido. Diferían claramente antes de Niza y parece meridiano que también después. Así, el ministro francés Védrine representa el eurorrealismo de abordar los problemas inmediatos sin alargar la vista a los grandes objetivos, mientras que el alemán Fischer refresca la vieja idea de los Estados Unidos de Europa con carácter federal, un presidente elegido por sufragio universal y un parlamentarismo bicameral (permanecería el actual Parlamento y la segunda cámara acogería a los representantes de los Estados miembros). En fin, modelos concretos al margen, hoy perviven fuertes resistencias en materias como una fiscalidad, una seguridad social, unos visados, un asilo e inmigración y una política comercial comunes. Distintos países, diversas políticas, diferentes modelos de unificación, mientras se acercaba la cita de Niza.

Hasta aquí parece contrastado que reflexionar a propósito del euro pasa por considerar la globalización, las políticas europeas, la crisis energética, la reforma de la UE o la omnicomprensiva presencia de la economía americana. Pero reflexionar ahora a propósito del euro pone encima del tapete, sobre todo, los delicados problemas internos de la UE que se sus- 
tantivan en una crisis institucional tanto de identidad como de crecimiento. A los Quince les agarrota el pragmatismo inmediato pero saben que el horizonte va más allá de las reformas acometidas en Niza para posibilitar la ampliación, y queda mucho horizonte por delante para la operatividad real del nuevo Tratado. Se ha manifestado (más los federalistas) que Europa buscaba una Constitución y se venían apuntando cuatro modelos, ya brevemente esbozados, entre quienes creen que la unificación ha tocado techo, sobre todo con la unión monetaria, y quienes aspiran a una mayor integración. Así, el Reino Unido (Blair) apuesta por un gran mercado intergubernamental: la Europa unida de los Estados y del libre mercado, que significa un proyecto más económico que político. Otro modelo lo representa el tradicional método francés de una Unión paso a paso sin prefijar un destino final y sin acometer más reformas que las inmediatas, avanzando siempre aunque sea «a ciegas». Un tercer modelo lo constituye el denominado núcleo duro (Delors, Schmidt, Giscard d'Estaing), consistente en la Europa de distintas velocidades, avanzando a través precisamente del núcleo duro de los países de la zona euro tras una profunda reforma institucional. Un cuarto modelo lo lidera el federalista Fischer que pasa por una federación de Estados con un Gobierno (el Consejo), una Constitución y un Parlamento bicameral repartiendo competencias entre niveles europeo, estatal y regional, «obviando» a la Comisión y conviviendo el actual entramado institucional para todos (socios y aspirantes) con las nuevas instituciones federales para el núcleo duro (doce o quince). Núcleo duro y distintas velocidades se han convertido, de hecho, en las expresiones más opacas de la actual etapa en la unificación europea. En ese ambiente y con esas posturas llegó la fecha de la Conferencia Intergubernamental en Niza (diciembre del 2000). Una cumbre que se ha convertido en la más larga y probablemente más conflictiva, pero también más clarificadora, de la Unión Europea. El resultado ha sido un futuro tratado como herramienta que adaptará las instituciones a una Europa no lejana de veintisiete miembros, consagrando el sistema de cooperaciones reforzadas que instala abiertamente un escenario de distintas velocidades. Alemania ha sido la impulsora del modelo resultante, y sobre el apoyo de su mayor peso demográfico podrá bloquear cualquier decisión si se une a dos de los países que han salido configurados, junto a ella, como grandes (Francia, Reino Unido e Italia). Esto, en principio, ha quebrado el tradicional equilibrio franco-germano, pero dicha quiebra ha quedado un tanto desdibujada por el enfrentamiento entre Pequeños y Grandes Europeos.

Reflexionar a propósito del euro al inicio del año 2001 obliga a efectuar algunas consideraciones sobre esta cumbre, aunque sin un análisis en detalle, pues se trata sólo de dejar constancia de cómo se pretende configurar la Europa del futuro inmediato en la que, de una u otra manera, antes o después, circulará una única moneda para todos o la gran mayoría de sus miembros. De Niza deviene, en síntesis, que el reparto de poder en la Europa ampliada lo encabezaría Alemania con 99 escaños en el Parlamento, 29 votos en el Consejo y 82.038 .000 habitantes; en ese escalafón va seguida del Reino Unido, Francia e Italia, los tres con 72 escaños en el Parlamento, 29 votos en el Consejo y unas poblaciones que ascienden a 59.247.000, 58.966 .000 y 57.612 .000 habitantes, respectivamente. España a continuación obtiene 50 escaños parlamentarios y 27 votos en el Consejo con una población de 39.394.000, ocupando un puesto de país intermedio junto con Polonia, que obtendrá a su ingreso idénticos escaños y votos (38.667.000 habitantes). Hay un salto notable hasta Rumania, que obtendría 33 escaños a su incorporación y 14 votos, a la que le sigue a distancia Holanda ( 25 escaños, 13 votos), y tras ella un grupo de cinco países con 12 votos en el Consejo, aunque diferente número de escaños (Grecia, Bélgica y Portugal, 22 escaños, y República Checa y Hungría, 20 escaños). Con 10 votos en el Consejo quedan Suecia, Bulgaria y Austria (18, 17 y 17 escaños, respectivamente), seguidos de otro grupo de cinco países con 7 votos (Eslovaquia, Dinamarca, Finlandia, Irlanda y Lituania), aunque los tres primeros obtienen 13 escaños parlamentarios y los dos últimos 12. El último grupo de cinco países, con 4 votos, lo conformarían Letonia, Eslovenia, Estonia, Chipre y Luxemburgo, aunque con 8, 7 y 6 escaños, respectivamente, en el orden citado. Cierra esta especie de ranking Malta con 5 escaños y 3 votos. Ello depara un total de 626 escaños en el Parlamento y 345 votos en el Consejo que se distribuyen en una lista como la reflejada a través de unos datos suficien. temente elocuentes. No parece necesario insistir que en esta configuración el peso demográfico ha sido al fin determinante.

En cuanto a la Comisión, no podrá superar el límite de 27 comisarios. Se han consagrado las cooperaciones reforzadas a fin de que algunos países puedan avanzar con más rapidez que los demás en las áreas que elijan; iniciativa esta cuyo principal promotor también ha sido Alemania. Bastará que ocho países acuerden avanzar en un área determinada para poner en marcha la iniciativa sin que ningún otro Estado pueda vetar una cooperación reforzada, aunque sí incorporarse a la misma. Es, al fin y al cabo, la cristalización, ya mencionada, del mecanismo utilizado para poner en marcha la moneda única o el espacio Schengen. El presidente de la Comisión será elegido por mayoría y no por unanimidad como hasta ahora. De sus actuales 20 miembros (dos por cada país grande y uno por cada pequeño), a partir del año 2005 se perderá uno por parte de cada país grande y se aportará otro por cada país que se incorpore a la UE. Las carteras serán ocupadas por cada miembro en turno rotatorio y el presidente refuerza notablemente sus poderes sobre los comisarios. Sin entrar a analizar el funcionamiento de las minorías de bloqueo, el sistema de veto y mayoría cualificada, el balance depara un Tratado de Niza que ratifica el despegue de Alemania sobre Francia y el resto de la Unión, el mayor peso general de los grandes, el mantenimiento de la cultura del veto, la instalación de dos clases 
de comisarios (no habrá carteras para todos), la previsión de otra profunda reforma en el año 2004 (podría ser la federal), la instalación de un triple sistema de bloqueo, pues, además de la suma de votos actual (26 sobre un total de 87 ), se añaden los votos que representen el 38 por 100 de la población y la mitad de Estados más uno, y la inclusión de la política exterior como una de las áreas de cooperación reforzadas, así como el mantenimiento de la fiscalidad bajo el sistema de veto. Los países del Este en general, aunque con alguna vacilación, se han manifestado satisfechos, mientras Portugal encabezaba el grupo de los que se proclaman descontentos. $Y$ en cuanto a España gana y pierde, si se considera que no forma parte de los grandes pero pasa de 8 a 27 votos en el Consejo.

En Niza ha primado, pese a haberse negado reiteradamente, la aritmética y el camino hacia el federalismo, pues Alemania ha trasladado a la UE la revisión de competencias en el 2004 entre la Unión y los Estados miembros tal y como exigen sus länder, suspicaces de que la integración desvirtúe el propio federalismo germano. Pero lo que Niza ha dejado entrever con mayor nitidez en sus larguísimas sesiones han sido un grupo de líderes nacionales practicando la alta diplomacia y proponiendo sus propios intereses en nombre de Europa. Aunque deba reconocerse que también así "se hace más Europa», por paradójica que pueda parecer esta forma de aunar y regir un continente lleno de micromundos.

\section{A propósito del escenario y la cotización del euro}

Mientras tanto la cotización del euro, a pesar de sus tímidas recuperaciones y de los favorables augurios de algunos analistas, todavía sigue un avatar incierto en función de otras variables del mercado, además de la psicología colectiva de cada Estado miembro y los distintos intereses de cada uno de ellos manifestados plausiblemente en la reforma del Tratado de Amsterdam y en la ampliación al Este, que tomaron camino decidido en Niza. Una cumbre que se planteaba en aquellos meses del 2000 dejando entrever profundas grietas entre los protagonistas, superadas sólo parcialmente tras su celebración, hasta el punto de haberse referido a ellas como «las heridas de Niza», sobre todo entre Francia y Alemania. Heridas que, sin embargo, se está tratando de restañar, conscientes tanto estos dos países como el resto de sus socios de que sin el motor franco-alemán bien engrasado resultará harto difícil la cohesión europea. La propia Alemania parece tener claro que no se basta sola para imponer su propia política para todo y a todos, pues cualquier decidido intento en dicho sentido pudiera incluso generar en su contra «peligrosas» alianzas entre otros países de la UE. Y a pesar de haber resultado claramente el país más beneficiado, difícilmente afrontaría en solitario los riesgos de una ampliación que, si se produce con excesiva precipitación, es probable llegara a afectar al euro, puesto que la sola consideración de la delicada situación del sector bancario en los países del Este cabalmente pudiera producir un efecto desestabilizador para la moneda única incluso con anterioridad a que los canditados soliciten su ingreso en la misma. El ejemplo lo tiene la propia Alemania internamente, pues se está constatando que la ex República Democrática necesitará al menos diez años para equipararse al sector occidental, a pesar de las cuantiosas transferencias que hacia ella se están canalizando. Era en este ambiente previo y simultáneo a la cumbre de Niza en el que la cotización del euro libraba sus más espinosas batallas.

Efectivamente, durante el otoño del año 2000, el BCE, tras subir sucesivamente los tipos de interés, intervino por primera vez en los mercados financieros adquiriendo 2.500 millones de euros, lo que repuntó su valor sin impedir nuevas caídas. No obstante, los dirigentes del Banco Central evitaron calificar esta actuación como una intervención de rescate, sino que la presentaron como una venta de los ingresos por intereses de las reservas de moneda extranjera de que fue dotado el banco a principios de 1999 (39.500 millones de euros, de las que un 15 por 100 era oro). Estos activos generaron unos intereses en dólares y yenes equivalentes precisamente a más de 2.500 millones de euros. El propio BCE, al intervenir, anunció su intención de continuar vendiendo, siempre que lo considerara necesario, futuros ingresos en concepto de intereses de activos extranjeros. La situación al inicio del otoño era tal que el Fondo Monetario Internacional y el Banco Mundial también solicitaron (septiembre), y se produjo, una intervención concertada en socorro del euro. Ambas instituciones manifestaron su alerta ante los riesgos de una economía mundial cada vez más interdependiente al presentar su Informe de Perspectivas Económicas (World Economic Outlook). Según dicho diagnóstico, el tirón en aquellas fechas (mediados del 2000) de la economía norteamericana, la robusta expansión de la UE (pese a algunos indicadores) y la recuperación de Japón (luego frenada) no debieran dejarse arrastrar por la escalada de los precios del crudo, la debilidad del euro o el déficit de Estados Unidos, a lo que añadieron casi proféticamente que pudiera sumarse una previsible crisis en la nueva economía de las telecomunicaciones. Previsión que tiende a confirmarse. En el análisis global que efectuaba el FMI, América Latina, Asia e incluso Africa se estaban recuperando a pesar del específico hundimiento de un buen número de países en dichos continentes. Así que, incidiendo de nuevo en la propiciada liberalización del comercio, esta descripción dibuja el entorno y la dirección en la que puede encuadrarse también la propuesta que efectuó la Comisión Europea en cuanto a tratar de eliminar todas las barreras comerciales que limiten las exportaciones de los países más pobres del planeta hacia la UE. Aunque de nuevo se inter- 
pusieron dificultades internas para convencer de tal iniciativa a los Estados miembros y al Parlamento. La Comisión, además, invitó a Estados Unidos, Canadá, Japón, Australia y Nueva Zelanda a aprobar un desarme arancelario semejante, del que, estima, se beneficiarían los 48 países menos favorecidos del mundo, de los cuales 39 pertenecen al área ACP (Asia-Caribe-Pacífico). Esto dejaría prácticamente sometidos a aranceles sólo armamento y municiones, mientras que el arroz, azúcar y plátano quedarían protegidos hasta tres años después de la entrada en vigor del desarme arancelario. Otra proposición que se trae aquí porque pudiera estimarse una declarada apuesta europea por el mercado como árbitro de la economía mundial. Más librecambismo en la propiciada globalización.

En tanto se pone en práctica el problemático diseño institucional futuro, el euro parece frenar ocasionalmente su tendencia a la baja con una mantenida inestabilidad que sugiere también ocasionales repuntes. Tras sucesivas intervenciones del BCE subiendo los tipos de interés, interviniendo conjuntamente con Canadá, Estados Unidos, Reino Unido y Japón (septiembre), y vendiendo activos, bastó una etapa de silencio de los responsables del $\mathrm{BCE}$ y de no intervención para que se agitara de nuevo la moneda. Otra vez se calificó al euro de moneda sin patria y se hablaba de monedas-refugio para las inversiones (dólar y franco suizo), quienes - se decía- huían de una divisa que llegó a depreciarse casi el 29 por 100 desde que comenzó a cotizar en enero de 1999 , mientras la inflación en la zona UEM tendía a dispararse hasta el 2,8 por 100 (la de España llegó a superar el 4 por 100). Precisamente el repunte inflacionario de la zona euro ha sido particularmente llamativo en Alemania (un 1,8 por 100 en agosto hasta el 2,6 por 100 de diciembre), lo que a pesar de todo le sitúa, junto con Italia y Francia, como países que a finales del año 2000 se situaban en la más baja inflación anual, en una escala europea encabezada por Irlanda (5,5 por 100) hasta llegar a Suecia (1,3 por 100). En cuanto a la cotización de la divisa, trasladada a términos monetarios de pesetas, la paridad con el dólar nunca estuvo más distante que en el otoño del año 2000, pues desde la primera devaluación del gobierno socialista en noviembre de 1982 , con un cambio de 109,8 pesetas-dólar, seguida de un máximo histórico en febrero de 1985 que llegó a 170, cuando entra en vigor el euro se cambia a 156,1 (enero de 1999), y a partir de ese punto el proceso es ascendente con picos que llegaron a alcanzar en octubre del 2000 un cambio de 200,29 pesetas-dólar. Cuando España ingresó en la Comunidad Europea (1986) el cambio estaba en 140 pesetas, coincidiendo con el segundo gobierno del PSOE, y al integrarse en el Sistema Monetario Europeo (1989) se cambiaba a 118,3 pesetas. Entre 1992 y 1993, en ocho meses, se efectuaron tres devaluaciones que, a pesar de todo, dejaba el dólar todavía en 133,9 a fines de 1994 . Desde 1995 a 1998 la crisis monetaria general conocida como «efecto tequila» llegó a deparar que se comprara un dólar con poco más de 90 pesetas. Una secuencia temporal bastante reveladora, aunque corresponda a una etapa en que la política monetaria todavía no la detentaba el BCE.

Repasados someramente los datos inflacionistas y la depreciación frente al dólar en términos de pesetas, habida cuenta el período tomado de partida —año 1982 - y que todavía a día de hoy nos acerca mejor a la percepción de la evolución que si se efectuara en euros, desde 1998 las economías europeas han seguido, pese a todo, creciendo (España, en enero del 2001, alcanza el 4,1 por 100 con un PIB por primera vez de 100,8 billones de pesetas), pudiéndose establecer con cautelas una media de 3,3 por 100 del PIB para el año 2000 en la zona euro, y aceptar con muchas más reservas una previsión cercana al 3 por 100 para el año 2001, junto con una apuesta razonada por la contención del desempleo. Sin embargo, siempre a remolque de la economía americana, el más notable repunte del euro frente al dólar cotizando por encima de 0,84 , con una ganancia del 2,4 por 100 , se produjo tras el frenazo en el crecimiento de la economía americana, cuyo PIB subió sólo un 2,7 por 100 en el tercer trimestre del 2000 , justo la mitad del ritmo de crecimiento de meses anteriores $(5,6$ por 100). Una desaceleración (para algunos frenazo y para otros clara recesión) en cierto modo controlada, pues obedece en gran medida a la estricta política monetaria de la Reserva Federal, reconduciendo el crecimiento para evitar tensiones inflacionistas; sobre todo cuando, tras los desconcertantes resultados de las elecciones presidenciales americanas y la adaptación a una nueva Presidencia, resulta más que arriesgado aventurar una nueva intervención concertada en ayuda del euro por parte de la Reserva Federal. Con Bush convertido en presidente de los Estados Unidos (desde el 20 de enero del 2001) habrá de administrarse la favorable herencia económica de Clinton consistente en diez años de crecimiento ininterrumpido, pleno empleo, inflación controlada y superávit presupuestario, aunque a todas luces no sea previsible ni de lejos mantener el 4 por 100 de crecimiento (media general estimada del período). Se trata de propiciar un suave aterrizaje que desvíe la probablemente mal calificada recesión, optando por actuar de manera más proteccionista o más liberal. El ambiente psicológico en Estados Unidos no es hoy tan optimista, y el ciclo de bonanza ha durado tanto que los ciudadanos americanos lo han llegado a considerar normal, de manera que todo lo que lo debilite generará una inquietante comparación con el pasado. El secreto pudiera seguir estando, pese a todo, en la permanencia de Alan Greenspan durante al menos tres años al frente de la Reserva Federal que dirige desde 1987, pues no en vano ha sido el artífice de una política económica que convirtió el déficit presupuestario en superávit, manteniendo el crecimiento, creando millones de puestos de trabajo, controlando la inflación y conteniendo los tipos de interés. La ralentización actual de la economía norteamericana pudiera ser coyuntural, a pesar de que el propio Greenspan, con su ya secular cautela, ha pronosticado un parón con reducción de dos o más puntos en el crecimiento de la economía 
mundial y específicamente de la de Estados Unidos, que pasaría del 5,5 al 2 por 100, sin descartar momentos más bajos (criterio de Sachs ya apuntado, aparte).

Pero el escenario del euro va más allá de Norteamérica. La herencia de Clinton, en fin, deja un experimento en marcha sin demostrar su tesis: que la difusión mundial del capitalismo americano a través de incentivos económicos fomentaría el cambio político (democracia al estilo americano). Es cierto que las crisis financieras de Asia y Rusia en 1998 superaron el derrumbe económico, pero todavía persiste una sensación de precariedad en la economía mundial mientras se desacelera la propia economía de Estados Unidos y Japón acomete una seria recesión calificada sin paliativos como modelo fracasado. China ha sido otro experimento sin resolver, sobre todo políticamente, a pesar de su apertura de mercados a las importaciones y su inmediata incorporación a la OMC. Se ha llegado a afirmar que la política exterior norteamericana se ha elaborado más en el Departamento del Tesoro que en el Departamento de Estado. Pero la vertiginosa marcha de la globalización arrasa, y los mercados súbitamente han sido más grandes y más rápidos, incluyendo economías muy inestables, por lo que el dinero huye de países con déficits elevados, con dudosa capacidad de devolver préstamos o con caos políticos instalados permanentemente, acudiendo a países más competitivos. Así sucedió en 1997 con la crisis thailandesa, que contagió al Sureste asiático y Corea del Sur, o a continuación en Rusia, así como el denominado efecto tequila de México. «El guardián» (Estados Unidos) se volcó en que los países se abrieran a las inversiones extranjeras y no cuidó tanto la forma de gestionar ese dinero. En definitiva, no se ha producido la pretendida nueva arquitectura financiera mundial, aunque haya habido ciertos cambios encabezados por la modificación de las prácticas de préstamos del FMI. La decisión (enero del 2001) de la Reserva Federal (de nuevo Greenspan) tras la disminución de la presión fiscal en cuanto a bajar los tipos de interés medio punto viene a confirmar muchas de las cuestiones planteadas. Que el frenazo de la economía americana tiene algunos perfiles de recesión, que su efecto arrastre es indudable (aquello del estornudo de Wall Street que provoca pulmonías en otros mercados), aunque para algunos pudiera resultar oportunamente beneficioso, y que la nueva economía también tiene ciclos, aun desconociéndose su duración y la capacidad de maniobra que permiten. Porque la política actúa secularmente con demasiado retraso respecto a la marcha de los mercados, y mientras que los problemas son globales, la política sigue siendo local. Delicado ajuste de tiempos y espacios, y más delicada adopción de medidas en un ciclo nuevo, poco conocido y menos pronosticable.

Éste es el escenario a principios del 2001 (quizás no el de mañana, ni el de hoy mismo por la tarde) en el que se estrenará, competirá y ampliará el euro. Sin embargo, al encarar el año 2001, si Estados Unidos se replegara de forma continuada habría que descubrir una nueva locomotora de la economía mundial y ésa - se apunta - podría ser la oportunidad de Europa, quien puede erigirse en un modelo de competitividad y, además, de solidaridad social. Sólo que esa oportunidad se vislumbra cuando su propio modelo se está transformando y la Unión Europea se ve sumida en profundas modificaciones internas salpicadas por una crisis de liderazgo además de una más que previsible instalada desaceleración económica. Y cuando no se muestra excesivamente clara ni la entidad, ni la duración, ni el efecto contagio del estancamiento estadounidense. Todo ello en un ciclo global cuyas coordenadas profundas resultan complicadamente analizables con rigor en el presente, cuanto más con rigor futuro. Expertos analistas y dirigentes se debaten en serias incertidumbres respecto a cuáles de las políticas públicas resultarán rigurosamente eficaces.

\section{A propósito de Europa}

En suma, la reflexión final, mirando de nuevo hacia adentro, conduce otra vez al pasado reciente y al futuro inmediato. Han sido y son una realidad las dificultades de los productos comunitarios en un medio de liberalización de mercados, porque el bienestar sigue «lastrando» su producción. Euro y Estado de Bienestar pueden aparecer así como polos contrapuestos. Pero la moneda única también está concebida como fortaleza teóricamente inexpugnable, entre otras cosas, para mantener el gasto social y competir. A veces se tiene la impresión de que para la puesta en marcha de la unificación monetaria se haya actuado con precipitación, pero ello bien pudiera obedecer precisamente a la inseguridad que provoca ese complicado y cambiante escenario internacional. Había que actuar. El TUE acabó con el tradicional principio comunitario de proceder por etapas planificadas muy cuidadosamente, de lo que es buena muestra cómo se han ido produciendo las sucesivas ampliaciones, siempre contando con el respaldo de la opinión pública, que ha respondido habitualmente de manera muy favorable con la excepción de Noruega. La UE ejerce todavía tal atractivo que muchos de los países de Europa oriental ingresarían ya si pudieran en el club de los Quince y en el de los Doce. Y ese atractivo parece mantenerse a pesar de las circunstancias negativas por las que atraviesa la moneda única. Es cierto que la unidad monetaria también favorece especialmente a Alemania y, en menor medida, a Francia. La primera, además de aproximarse a su viejo sueño de la Europa supranacional, se convierte en un polo magnético para los países de Europa Central y Oriental, tan temerosos siempre de la potencia germana. Francia, por su parte, trata de superar su tradicional «rivalidad-temor» frente a su vecino, poniendo fin a un encubierto «complejo de inferioridad» sólo enjugado con la «grandeur». Con el euro, 
pues, se compra en cierto modo seguridad. Puede que también ahí se instale la explicación a la celeridad de la unión monetaria y la prisa por la ampliación, porque es una forma no meramente económica de dar respuesta al «temor» que Alemania se tiene a sí misma y al que le profesaba (¿profesa?) Francia. A veces puede suscitarse la impresión de que se intentaran reproducir los movimientos unificadores del siglo XIX (Alemania-Italia). Pero la Unión Europea está conformada por un conjunto de naciones-naciones cultural y estructuralmente muy heterogéneas, con un añadido componente interno regional nacionalista, y que en no pocos aspectos están distanciadas, cuando no enfrentadas. La barrera entre esas naciones tiene un perfil más cultural que económico, sobre lo que el propio Jean Monnet reflexionó que, si se pudiera reiniciar el proceso de unificación, habria de hacerse por la cultura y no por la economía; reflexión un tanto utópica aun entendiendo la necesidad del argumento. La celeridad, rayana en la impaciencia, de la unificación monetaria (y ahora de la ampliación) no es el único punto débil del proceso. Ha de tenerse en cuenta que la UEM se puso en marcha en una época de crisis con perfiles muy definidos, por lo que la moneda única pudiera haberse erigido también en una especie de panacea, incluso frente a posibles confrontaciones entre sus miembros. Pero Europa, desde la Segunda Guerra Mundial, ha experimentado tales cambios socioeconómicos y políticos que le han convertido en algo irreconocible, de modo que, situando en primer lugar el impacto de la caída del comunismo, los Quince son hoy democracias consolidadas que han cedido voluntariamente parcelas de su soberanía en aras de lo que podría denominarse intereuropeísmo, y además lo han efectuado de forma, en general, cuidadosamente ralentizada, sólo acelerada precisamente con la unificación monetaria, pues la ampliación ratificada en Niza marca otro ritmo aunque también sea rápido.

De todo ello se concluye que con reflexiones e interrogantes, y a pesar de ellos, el dramatismo de ciertas corrientes maximalistas no parece tener cabida y se vislumbra una futura realidad supranacional operativa, con independencia de si tuviera carácter más federal o intergubernamental. Y el euro, a pesar de su volatilidad cercana a la labilidad y de los repetitivos varapalos cambiarios frente al dólar, debe y puede funcionar como un decisivo instrumento de cohesión europea. La complejidad técnica, económica y política del proceso suscita un debate de fondo sobre lo que realmente se está ventilando, pero dicho debate no puede enturbiar su entidad, sino aportar soluciones en un camino irreversible, aunque reconductible en múltiples aspectos y en el que los euroentusiastas y eurodetractores encuentran difícil acomodo. En un momento se llegó a calificar al euro de moneda abandonada, pero ya se había previsto en el momento de su creación que la inestabilidad del tipo de cambio frente al dólar sería en un futuro más complicada y severa. La economía americana produce un indudable efecto contagio o arrastre, pero también falta en Europa una clara combinación de política monetaria única y políticas presupuestarias diversas que los economistas denominan «policy mix». Sólo en este sentido cabría, siempre con reservas, el dramatismo de quienes aseveran que la UE no está gobernada y sufre un notable desequilibrio institucional. A su vez, el BCE es un poder tecnocrático y constitucional que adolece de una insuficiente legitimación política, lo que le ha conducido a elegir soluciones de compromiso que satisfagan a todos o la mayoría de los países miembros, minimizando habitualmente los riesgos. En las situaciones de más baja cotización del euro podría no haber tocado los tipos de interés y esperar a una sólida recuperación europea, o por el contrario haber llevado a cabo un drástico aumento de los tipos, pero hubieran sido medidas excesivamente resolutorias. Y los mercados no parecen entender la lógica monetaria europea ni la continua lucha por la credibilidad del BCE. Sin embargo, todo indica que no habría de repetirse el error de los años noventa aplicando otra vez políticas restrictivas que frenen el crecimiento, décimas que pueden parecer insignificantes, pero que permitirían, entre otras cosas, el mantenimiento e incremento del empleo para un buen número de ciudadanos. La preocupación es que los problemas del euro terminen siendo los del BCE y la actitud de esta institución sea objeto de permanentes dudas. Como permanentes dudas suscita lo que ya se está denominando la cuestión post-Niza y sus silencios, sólo interrumpidos por «gritos» de disensión. Habría de cuestionarse si la política monetaria es la receta que puede curar la economía europea con una tasa de inflación del 3,4 por 100 , la más alta desde 1993, y una previsión de crecimiento a la baja de hasta el 1,3 por 100 . Resulta muy tentador aplicar los rápidos ajustes que proporciona la política monetaria, pero cada vez más se demuestra que la mejor forma de lograr un crecimiento sostenido estriba en manejar los factores que conforman el potencial de crecimiento: ambiente laboral, capital, conocimiento y la eficiencia con la que todo ello se emplee. En definitiva, manejar factores estructurales: mercados competitivos y un marco de políticas públicas que promuevan los negocios. En Europa, la injerencia de los Estados en las economías todavía es elevada y deriva en una también elevada presión impositiva, además de una intensa y poco flexible regulación laboral y salarial, así como un comparativamente sensible retraso tecnológico. Ello parece apuntar que la clave pudiera residir en la aplicación de un programa integral de reformas estructurales coordinadas que deparen un marco macroeconómico estable.

El euro no ha acabado, ni parece haberlo pretendido, con los ciclos de alzas y bajas en las variables macroeconómicas que determinan épocas coyunturales de recesión y expansión económicas en un mundo progresivamente más interdependiente en el que todos estamos supeditados a las variaciones en los niveles de intercambio de los distintos mercados internacionales, y en el caso europeo, especialmente a las variaciones del mercado norteamericano, por lo que ha parecido razonada 
la actitud de cierto nerviosismo frente al hasta ahora alza sostenida en los mercados de cambio de la divisa norteamericana a través de la cual tienen lugar diariamente un elevadísimo porcentaje de las transacciones mundiales. Pero también se entiende razonadamente que las economías nacionales en otro marco afrontarían con mayor dificultad cualquier situación, y si el euro se debate por hacer frente a coyunturas desfavorables, nuevas, vertiginosas y desconocidas, sin duda operará como un baluarte de mayor consistencia y un instrumento de mejor operatividad. Máxime en el inmediato y posiblemente esperanzador futuro que pudieran depararle los acontecimientos recientes y la propia presumible tendencia del ciclo. Es cierto que los mercados de dividas son extremadamente complejos e incognoscibles a corto $\mathrm{e}$ incluso a un año vista, pero si Europa no consigue convertirse en el vehículo racional de una cultura y unos intereses comunes, su moneda será un simple instrumento de cambio en vez de un depósito de valor.
En definitiva, ni euroentusiastas ni eurodetractores, sino reflexiones razonadas que coadyuven a un debate de fondo y a una búsqueda de respuestas sucesivas a través de políticas públicas específicas, tanto frente a los interrogantes planteados a lo largo de esta exposición como a los que, sin haberlos planteado, sin embargo ejercen una indudable influencia y parece que van a seguir ejerciéndola al menos a medio plazo. La unificación europea - también la monetaria - a pesar de sus indudables grietas, ha adquirido madurez suficiente como para poder encontrar respuestas selectivas a los interrogantes que se planteen. Ése es el papel de las políticas públicas contrastadas. Y cualquier reflexión razonada a propósito de la moneda única se puede erigir en instrumento de trabajo aunque no esté exenta de dudas y de carga crítica. O precisamente porque conlleve unas y otra.

Febrero 2001.

\section{* Instituto de Estudios Fiscales.}

Nota del autor. Desde febrero del 2001 en que se elaboran estás reflexiones hasta que se produzca su publicación vienen sucediéndose una serie de acontecimientos ciertamente influyentes pero que, por haber sido indicados, apenas han modificado lo enunciado en el artículo:

- La victoria electoral del partido laborista en el Reino Unido en junio está esbozada y razonada en el texto, así como que de ella no se derivaría la celebración inmediata de ninguna consulta popular para la incorporación inglesa a la moneda única. Aunque Blair lance globos sonda y los tories hayan calificado la victoria laborista como un referéndum encubierto para entrar en el euro, la situación reciente del laborismo triunfante respecto al euro se resume por el momento en su mensaje de que se puede ser patriota sin libras en el bolsillo.

- El mismo mes de junio la negativa irlandesa a la ampliación de la UE gestada en Niza, expresada mediante referéndum, a pesar de su carácter sorpresivo, está también apuntada en el texto como posible al considerarse la desviación de fondos comunitarios que iba a implicar la incorporación de los países del Este europeo y mencionar la peculiar política económica de Irlanda. Los recientes desencuentros y tensiones germano-españoles tienen también como sustrato el problema de los fondos comunitarios, aunque con otras connotaciones añadidas de indole política. Tras la cumbre de Gotemburgo, los últimos meses del 2002 van a presenciar el primer examen de la ampliación y Berlín 2004 será el horizonte. El problema sigue estribando en cómo se va a llegar a él. La ampliación ha vuelto a desnudar una realidad donde encuentra difícil cabida el euroentusiasmo.

- El reiniciado debate entre los Estados miembros sobre el modelo político-organizativo de la futura Unión no ha venido más que a abundar, con algunos matices, en las posturas encontradas antes de la Conferencia de Niza y romper el silencio forzadamente triunfalista posterior, lo que también está descrito en el texto. Las «heridas de Niza» no parece ser sólo una expresión más o menos desafortunada. Francia y Alemania, tan de acuerdo para defender sus intereses frente a otros países miembros, se separan en cuanto se aborda la organización interna de la UE y el concepto de federalismo. El modelo de Estados-Nación de Jospin choca con el federalismo a la alemana de Schröder, mientras la Comisión Europea lanza la idea del «contrato tripartito» con los Estados y los gobiemos de las regiones y autonomías en el Libro Blanco de la Gobernanza a través de la modificación del funcionamiento del Comité de las Regiones. Inglaterra es progresivamente más atlántica que europea, mirando hacia Estados Unidos, y aunque Londres se muestre partidaria a entrar en el euro, la City está más cerca de Wall Street que de Francfurt. Holanda, Bélgica y Luxemburgo se aproximan a Alemania y Francia de tal manera que cuanto más retórica se hace sobre la ampliación, más parece que se vuelve realmente a la Europa de los seis países primigenios, quienes aceptarian un liderazgo estadounidense, pero no su hegemonía.

- La cotización del euro persiste en su volatilidad a pesar de la desaceleración de la economía americana, que tras sucesivas bajadas del precio del dinero (desde el 6,5 al 2,5 por 100) y la ralentización del crecimiento (1,3 por 100) asimila, asume y soporta una inflación superior al 3 por 100 , sin hundirse claramente en severa recesión. La cotización del euro vuelve a poner en entredicho la comen. tada cuestionabilidad de la política monetaria del BCE y su maltrecha credibilidad, aunque la política monetaria de Greenspan también esté cada vez más en entredicho y no termine de solucionar el problema de fondo de la economía nor. teamericana. Nueve bajadas del tipo de interés efectuadas por la Fed se corresponden casi en matemática secuencia con la política del BCE, que contrariamente a su política anterior ha rebajado un cuarto de punto los tipos el mismo dia (30 de agosto) que efectuó la presentación de los billetes reales de euros, dejando el precio del dinero en el 4,25 por 100 para tratar de frenar la desaceleración económica europea. Con todo, lo más llamativo han sido los datos de desempleo en Estados Unidos (un incremento del 4,9 por 100 en agosto), lo que depara 6,9 millones de personas buscando trabajo (1,2 millones más que el año anterior). Al tiempo, Japón se enfrenta a su cuarta recesión en diez años con una caída del 3,2 por 100 anual en el PIB y un paro del 5 por 100 de la población activa, nivel al que no se había llegado desde la Segunda Guerra Mundial. La crisis de la economia digital y la ralentización del sector de altas tecnologias arrastran a la economía real en la línea anunciada en el texto, y la falta de expectativas de empleo reduce el consumo de los ciudadanos, que es lo que está ahora sosteniendo, aunque sea precariamente, la coyuntura y no la inversión (la producción industrial del G-7 es decreciente). El círculo se cierra en asfixia cuando los ciu dadanos dejan de consumir, se reduce consecuentemente la demanda interna $y$ los beneficios empresariales, y se incrementa el paro.

- Los datos de precios en Europa confirman que la inflación continúa cons tituyendo el gran problema económico de la UE y específicamente de la UEM. Alemania alcanza el 3,5 por 100 y Francia el 2,3 por 100 , mientras las previsiones de crecimiento del BCE le dejan entre el 2,2 y 2,8 por 100 (antes entre el 2,6 y 3,6 por 100). Una cuestión a plantearse es si con dichos datos el término estan. flación aplicada por algunos analistas a la economía estadounidense pudiera ser un calificativo que emigrara a Europa. Para ciertos sectores el problema sigue siendo definir un dilema ya clásico en economía: si hay que priorizar el apoyo al crecimiento o el frenazo a la inflación. La sombra del desempleo empieza 
a amenazar y la negativa de Duisemberg a la necesidad de revisar el Plan de Estabilidad y Crecimiento puede indiciar un sintoma.

- En cuanto a la antiglobalización, la cumbre de la UE en Gotemburgo (junio) ha sido testigo de violentas manifestaciones de muy diversos colectivos. No obstante la violencia y diversidad de los gritos (también contra el euro), los líderes europeos accedieron a dialogar con los manifestantes. Una y otra actitud pueden enmarcarse en la línea de lo descrito a lo largo del artículo. Sin embargo, aun habiéndose apuntado que cualquier reunión de las altas instituciones financieras mundiales atraería sistemática y consecutivamente a la amalgama de grupos que conforman el movimiento antiglobalización, la reunión del G.8 en Génova ha superado cualquier previsión. Globalización y antiglobalización ya cuentan con la primera muerte (un manifestante) y Génova, en fin, ha revelado quiénes se aglutinan tras la antiglobalización, pero sobre todo cómo la politica una vez más llega tarde y mal.

- La «resurrección» de la tasa Tobin por antiglobalizadores y algunas izquierdas europeas ha provocado que su autor haya salido a puntualizar una serie de cues. tiones (Der Spiegel, agosto del 2001). Tobin se declaraba, en nombre de su profesión de economista, partidario del libre comercio y de la experiencia de ins. tituciones como el FMI, BM y OMC, incluso apuntando que no son, como se ha pretendido, los líderes de una especie de conspiración denominada globa. lización ni enemigos de los países pobres, sino que incluso el FMI, a pesar de los errores cometidos, debiera ser ampliado y reforzado para conducir, si se llevara a cabo, una hipotética aplicación de su tasa. Reclama mayor poder para la OMC, incluso sobre Estados Unidos, a fin de poder prohibir el bloqueo por los países industrializados de las importaciones procedentes de los paises en vías de desarrollo. Niega que el libre intercambio de mercancías y capital haya generado mayor pobreza en el mundo poniendo como ejemplo, a pesar de la crisis, la situación global comparativa de Corea del Sur y otros «Tigres Asiáticos» en 1960 y la de hoy. Derrumba la idea de los antiglobalizadores en cuanto a que la pobreza deviene absolutamente de los países ricos y desarticula soluciones como la implantación de las normas occidentales para los puestos de trabajo en los países pobres, porque —dice— reduce la competitividad de sus exportaciones a los países más favorecidos. No aboga por el regreso a los tipos de cambio fijos tras el fracaso del intento para reponerlos. Niega que una moneda única como el euro sea una solución exportable a otras áreas del mundo, mostrándose crítico con el $\mathrm{BCE}$ y Duisemberg en contraposición con la política de la Fed y de Greenspan, hasta el punto de argumentar que el alejamiento del BCE de la economia real centrándose sólo en la inflación y abandonando el crecimiento y el empleo al estilo de los monetaristas americanos, de quienes se separó Greenspan, es donde reside el mal momento de la economía europea y, por contra, el éxito de la década Clinton. Es ésta una interpretación de la que se deja constancia oportuna aquí a propósito del futuro enfoque y utilización que se pudiera efectuar de la tasa Tobin.

- Mientras tanto China, que aparece por el momento como única potencia escapada de la crisis global, ha sido admitida (septiembre) como miembro de la OMC tras largas negociaciones.

- En cuanto a la dificultad de análisis del ciclo actual y la mucha más difícil elaboración de previsiones acertadas, viene a confirmarse en el denominado enfriamiento global de la economía. Efectivamente, desde finales de los años setenta, coincidiendo con la segunda crisis petrolífera, no se había producido que los tres grandes bloques (Europa, Estados Unidos y Japón) se encontraran en una coyuntura negativa simultánea. $Y$ no hay una respuesta válida porque se han derrumbado las afirmaciones de que habían desaparecido los ciclos, que las inversiones tecnológicas resistirian las recesiones y que la productividad y los beneficios empresariales seguirian creciendo. Las políticas económicas parecen no saber qué medidas aplicar, debatiéndose entre la estimulación y el rigor. Los analistas han quedado seriamente en entredicho.

- Sin embargo, los impactantes acontecimientos del 11 de septiembre en Estados Unidos y sus consecuencias sí modificarán no sólo lo descrito en el texto, sino el previsible escenario mundial, convirtiendo en auténtica entelequia cualquier análisis razonado de futuro a cualquier plazo imaginable.

Septiembre 2001

\section{Bibliografía}

Aguirre Rodricuez, J. A. (1990), La moneda única europea, Madrid: Unión Edjtorial.

ArjaAdo, M. (1998), La Unión Económica y Monetaria europea: mitos y realidades, Pirámide.

- (1999), Una bistoria de la Unidad Europea. Desde los precedentes remotos a la Unión Monetaria, Pirámide.

Amjado, M., y Osuna, R. (1999), La ampliación al este, I, Teoria de la transición, bechos estilizados y el punto de vista comunitario, Madrid: Pirámide.

- (1999), La ampliación al este, II, Europa central y oriental. Paises bálticos. Chipre y Turquia, Madrid: Pirámide.

Arujado, M., y Gonzàlez Ibán, R. (1999), El Banco Central Europeo y la política monetaria común: El Banco que gobernará Europa, Pirámide.

Alemany Zarazoza, E. (1999), Todo sobre el euro, Barcelona: Praxis.

Anchuelo Crego, A. (1999), Consecuencias económicas del euro, Madrid: Biblioteca Civitas Economía y Empresa, col. Economía, Civitas.

BAyOUMi, T., y EICHENGREEN, B. (1992), «Shocking aspects of European monetary integration", CEPR Discussion Paper, 643.

BEGG, I., y MAYES, D. (1991), «Social and Economic Cohesion among the regions of Europe: the case of Poland», Economic Policy.

Betz, H. G. (1990), «Mitteleuropa and post-Modern European Identity», New German Critique.
Bofinger, P. (1994), «Is Europe an Optimun Currency Area?», En A. STEINHERR (ed.), 30 years of European monetary integration: from the Wemer Plan to EMU, Londres.

Boletin mensual: Banco Central Europeo, Madrid: Banco Central Europeo-Banco de España, 1999.

BULMER, S. (1997), «History and institutions of the European Unión», en M. ARTIS y N. LEE, The economics of the European Union, Oxford: Oxford University Press.

Campessus, M. (1998), «Consecuencias mundiales de la UME», Cuademos de Información Económica, núm. 138.

Caruana LACORTE, J. (1997), «La UEM: el proceso hacia la moneda única», Cuademos de Actualidad, núm. 2, año VI.

COMUNIDAdes Europeas (1995), Unión Europea. Recopilación de los Tratados, Luxemburgo.

Diaz SalDaña, N. (1997), Los efectos del euro en los sectores productivos españoless, Madrid: Arthur Andersen, Instituto de estudios Económicos.

Domingo Solans, E., y Garcia Herrero, A. (2000), «La nueva política monetaria del eurosistema», Papeles de Economía Española, núm. 84-85.

«El desafío de la moneda única europea», Dirección y Progreso, núm. 104, marzo-abril 1989.

El euro, nuestra nueva moneda, Central Hispano, 1998.

Emerson, M., et al. (1992), One Market. One Money, Oxford: Oxford University Press. 
ESCRIBA, J. L.; FuENTES, I., y GUTLERREZ, F. (1997), «El sistema bancario español ante la Unión Monetaria Europeas, Banco de España, Estudios Económicos, núm. 59.

España en el euro, Economistas, núm. 78, 1998.

«España y el euro: riesgos y oportunidades», Informe mensual, 191, La Caixa, abril 1997.

«Euro, convergence et politique économique», Distribución y Consumo, núm. 43, año 9, 1998.

European Commission (1997), Agenda 2000, vol. I, Por una Unión más fuerte y más amplia, Documento COM (97) 2000, Bruselas.

Fondo Monetario Internacional (FMI) (1998-1999), World Economic Outlook, Washington.

Garton Ash, T. (1986), «Does Central Europe Exist?», New York Review of Books.

Gonzallez Minguez, J. M., y Santillán Fralle, J. (1998), El papel del euro en el sistema monetario intemacional, Madrid: Banco de España, documento de trabajo 9818.

Gowland, D.; O'Neml, B., y Reid, A. (1995), The European Mosaic: Contemporary politics, Economics and Culture, Longman.

Gros, D., y ThygeSEN, N. (1998), European Monetary Integration, 2." ed., Long. man.

Herce, J. A. (1998), «El Pacto de Toledo tres años después: el largo plazo y el euro», Cuademos de Información Económica, núm. 138.
«La ecu: evolución y perspectivas de futuro», Boletin Económico del Banco de España, núm. 5, mayo 1989.

«Le prix de l'euro», Rerue d'economie politique, núm. 2, 1998.

L'euro concretement, Bruselas: Générale de Banque, 1997.

LUTZELER, P. M. (ed.) (1995), Europe after Maastricht: American and European Perspectives, Berghanhn.

MaCDONal, S. (ed.) (1993), Inside European Indentities, Berg.

Maddison, A (1991), Dynamic Forces in Capitalist Development. A long-Run Comparative View, Oxford: Oxford University Press.

«Número especial dedicado al euro y la Unión Monetaria», Noticias de la Unión Europea, núm. 175-176, 1999.

Palazuelos, E. (1991), El cambio económico en el Este: resultantes actuales y esce. narios, en WVA.

Perspectivas de la economía mundial. La turbulencia financiera y la economia mundial: el euro, perspectiva y desafios, Washington: Fondo Monetario Internacional, Estudios Económicos y Financieros, 1998.

Requeijo GonzÁlez, J. (1998), El euro y la economía española: esperanzas e inquietudes, Madrid-Barcelona: Marcial Pons.

Samon, T., y Nicoll, W. (eds.) (1997), Building European Union. A documentary bistory and analysis, Manchester: Manchester University Press.

Serrano PASCUAL, M. (1999), El nacimiento del euro, Tapia, año 18, núm. 1003. THODY, Ph. (1997), An bistorical introduction to the European Union, Routledge. 
。 